\title{
Evidence for transient, local ion foreshocks caused by dayside magnetopause reconnection
}

\author{
Yann Pfau-Kempf ${ }^{1,2}$, Heli Hietala ${ }^{3}$, Steve E. Milan ${ }^{4}$, Liisa Juusola ${ }^{1}$, Sanni Hoilijoki ${ }^{1,2}$, Urs Ganse ${ }^{5,1}$, Sebastian von \\ Alfthan $^{6}$, and Minna Palmroth ${ }^{1}$ \\ ${ }^{1}$ Earth Observation, Finnish Meteorological Institute, Helsinki, Finland \\ ${ }^{2}$ Department of Physics, University of Helsinki, Helsinki, Finland \\ ${ }^{3}$ Department of Earth, Planetary, and Space Sciences, University of California, Los Angeles, USA \\ ${ }^{4}$ Department of Physics and Astronomy, University of Leicester, Leicester, UK \\ ${ }^{5}$ Department of Physics and Astronomy, University of Turku, Turku, Finland \\ ${ }^{6} \mathrm{CSC}$, IT Center for Science, Espoo, Finland \\ Correspondence to: Yann Pfau-Kempf (yann.kempf@helsinki.fi)
}

Received: 20 May 2016 - Revised: 31 August 2016 - Accepted: 17 October 2016 - Published: 4 November 2016

\begin{abstract}
We present a scenario resulting in time-dependent behaviour of the bow shock and transient, local ion reflection under unchanging solar wind conditions. Dayside magnetopause reconnection produces flux transfer events driving fast-mode wave fronts in the magnetosheath. These fronts push out the bow shock surface due to their increased downstream pressure. The resulting bow shock deformations lead to a configuration favourable to localized ion reflection and thus the formation of transient, travelling foreshock-like field-aligned ion beams. This is identified in two-dimensional global magnetospheric hybrid-Vlasov simulations of the Earth's magnetosphere performed using the Vlasiator model (http://vlasiator.fmi.fi). We also present observational data showing the occurrence of dayside reconnection and flux transfer events at the same time as Geotail observations of transient foreshock-like field-aligned ion beams. The spacecraft is located well upstream of the foreshock edge and the bow shock, during a steady southward interplanetary magnetic field and in the absence of any solar wind or interplanetary magnetic field perturbations. This indicates the formation of such localized ion foreshocks.
\end{abstract}

Keywords. Interplanetary physics (planetary bow shocks) - magnetospheric physics (magnetosheath; solar windmagnetosphere interactions)

\section{Introduction}

The super-Alfvénic solar wind impinging upon the geomagnetic field is slowed down and diverted around the Earth by the bow shock which forms upstream of our planet. Most of the plasma is abruptly compressed and heated by the shock while being transported downstream into the magnetosheath. There, it flows along the magnetopause surface, which delimits the magnetosphere, that is, the magnetic cavity in which the Earth is situated.

Fluid theories such as ideal magnetohydrodynamics imply that no wave or matter can travel upstream from a shock. However, it is well-known observationally and explained by kinetic plasma theory that, given a high enough Mach number and a small enough angle $\theta_{\boldsymbol{B}-\boldsymbol{n}}$ between the upstream magnetic field $(\boldsymbol{B})$ and the shock normal direction (n) $\left(\theta_{\boldsymbol{B}-\boldsymbol{n}} \lesssim 40-60^{\circ}\right.$, e.g. Greenstadt et al., 1980; Schwartz et al., 1983), a fraction of the incoming ions is reflected by the shock surface and streams back along the magnetic field direction. The region where such a backstreaming ion population exists is called the ion foreshock. It is the stage for a variety of plasma beam instabilities generating waves and has been studied observationally as well as in simulations for several decades (e.g. Bavassano-Cattaneo et al., 1983; Sanderson et al., 1983; Thomsen et al., 1983; Fuselier et al., 1987; Le and Russell, 1992; Eastwood et al., 2005b; Burgess et al., 2012; Wilson et al., 2013). The value of $\theta_{\boldsymbol{B}-\boldsymbol{n}}$ allowing the reflection of particles is dependent on several factors, 
among which most notably is the assumed reflection mechanism, as the results of Greenstadt et al. (1980), for example, show.

The bow shock under steady solar wind conditions is generally assumed to be a simple surface such as a paraboloid with a dawn-dusk asymmetry primarily due to the Earth's orbital motion. This follows from fluid dynamical considerations, numerical simulations as well as statistical studies of spacecraft observations. The inherently local nature of spacecraft measurements compared to the spatial scale of the bow shock, even in the case of spacecraft constellations such as Cluster (Escoubet et al., 1997), Time History of Events and Macroscale Interactions during Substorms (THEMIS; Angelopoulos, 2008) or the Magnetospheric Multi-Scale (MMS; Burch et al., 2016a) missions, does not allow us to determine the global shape of the bow shock surface at a given instant in time. Statistical studies are the method of choice (e.g. Merka et al., 2005; Meziane et al., 2014). Thus it is also usually assumed that under steady conditions, the ion foreshock is located in the solar wind volume magnetically connected to the bow shock surface region where $\theta_{\boldsymbol{B}-\boldsymbol{n}} \lesssim 50^{\circ}$. Depending on the orientation of the interplanetary magnetic field (IMF), this can be one or two compact regions in space.

Another tenet of ideal magnetohydrodynamics is the conservation of magnetic field line topology, which is a good assumption on large scales or in collisional plasma but breaks down on smaller scales when strong magnetic field gradients are present. Through the kinetic process of magnetic reconnection, antiparallel magnetic field lines rearrange their topology while strongly accelerating inflowing plasma out of the reconnection region (see, e.g., reviews by Zweibel and Yamada, 2009, and Treumann and Baumjohann, 2013, and references therein). A prime example of magnetic reconnection in near-Earth space occurs at the magnetopause in the subsolar region, when inflowing southward IMF reconnects with the northward-oriented geomagnetic field lines (e.g. Phan et al., 2000; Paschmann, 2008; Dunlop et al., 2011). This phenomenon drives global magnetospheric dynamics as first proposed by Dungey (1961), and therefore it is key to space weather studies (e.g. Cassak, 2016; Burch et al., 2016b).

The topological reconfiguration of magnetic field lines at the magnetopause can lead to the formation of well-delimited structures called flux transfer events (FTEs). The classic picture of an FTE is that of a magnetic flux tube connected both to the magnetosheath and the magnetosphere, but its topology can be more complex. FTEs were first observed by Russell and Elphic $(1978,1979)$ and Haerendel et al. (1978) (who termed the process magnetic flux erosion) and subsequently much studied in space and ground observations as well as simulations (e.g. Kawano and Russell, 1997; Wild et al., 2001, 2003; McWilliams et al., 2004; Fear et al., 2009; Eastwood et al., 2016; Hasegawa et al., 2016; Milan et al., 2016). FTEs travel downstream along the magnetopause with the magnetosheath plasma and are recognized by their signature in magnetic field measurements, such as the bipolar deflection of the component normal to their axis in the case of a flux rope or magnetic island (e.g. Omidi and Sibeck, 2007; Dorelli and Bhattacharjee, 2009; Sibeck and Omidi, 2012; Eastwood et al., 2012). Their signatures also include poleward moving auroral forms (PMAFs) and their equivalent in radar observations named poleward moving radar auroral forms (PMRAFs), which result from poleward ionospheric flows. Oscillations can also be observed by ground magnetometers (e.g. Øieroset et al., 1996; Milan et al., 2000; Pang et al., 2009). Although their role is crucial in the solar windmagnetosphere interaction, allowing plasma exchange along the reconnected magnetic field lines, FTEs have not so far been thought to be the direct cause of significant upstream effects.

In this work, we propose a scenario by which dayside magnetopause reconnection generates FTEs, which in turn cause steepening fast magnetosonic bow and stern waves to propagate throughout the magnetosheath. The increased pressure behind the steepened wave fronts causes the bow shock to bulge outward in an area travelling along the bow shock surface. The geometry at the edge of such a bulge can lead $\theta_{\boldsymbol{B}-\boldsymbol{n}}$ to become smaller than $\sim 50^{\circ}$ in a well-delimited region, detached from the "regular" foreshock, upstream of which a beam of reflected ions generates a local, transient and travelling foreshock. This chain of processes has first been identified in a two-dimensional polar-plane hybrid-Vlasov simulation of steady southward IMF interacting with an Earth-like dipolar magnetic field. The simulation was performed using the Vlasiator model (http://vlasiator.fmi.fi). We also present observational data supporting the scenario. Geotail spacecraft observations show the existence of short foreshock-like ion beams during steady southward IMF, in a region welldetached from both the bow shock and the regular ion foreshock region and in the absence of any IMF fluctuations, thus excluding a momentary transit of the spacecraft through the regular foreshock due to a change in IMF orientation. Simultaneously, the signatures of FTEs moving poleward are found in ground magnetometer and SuperDARN (Super Dual Auroral Radar Network) radar data.

Section 2 describes the simulation and the observational methods. The scenario of magnetopause-bow-shockforeshock interaction is detailed in Sect. 3, while the ground and spacecraft observations are presented in Sect. 4. The results are then discussed in Sect. 5 before the conclusions are given in Sect. 6.

\section{Methods}

\subsection{Hybrid-Vlasov simulation}

The hybrid-Vlasov model Vlasiator has been developed with the aim of producing global magnetospheric simulations 
of the Earth's magnetosphere including kinetic physics beyond magnetohydrodynamics while avoiding the limitations due to the statistical sampling inherent to particle-in-cell approaches (von Alfthan et al., 2014). Vlasiator has been used to study amongst other things the magnetosheath and the foreshock in equatorial plane simulations of the terrestrial magnetosphere (Pokhotelov et al., 2013; Kempf et al., 2015; Palmroth et al., 2015; Hoilijoki et al., 2016). It solves Vlasov's equation to propagate the ion (proton) velocity distribution function in up to three spatial and three velocity dimensions. The equation system is closed via Ampère's and Faraday's laws as well as a generalized Ohm's law including the Hall term (see von Alfthan et al., 2014, and Palmroth et al., 2015, for more details).

The simulation used in this study is two-dimensional in the polar $x-z$ plane and three-dimensional in velocity space. It covers both the dayside and the nightside magnetosphere. The spatial coordinates are similar to the Geocentric Solar Magnetospheric (GSM) coordinate system with the $x$ axis pointing from the Earth towards the Sun and the $z$ axis orthogonal to the $x$ axis and parallel to the geomagnetic dipole field axis (no dipole tilt). We use a two-dimensional line dipole centred at the origin and scaled to match the geomagnetic dipole strength in the same way as is done by Daldorff et al. (2014). The steady solar wind has a proton density of $1 \times 10^{6} \mathrm{~m}^{-3}$, an inflow temperature of $0.5 \mathrm{MK}$ and a velocity of $-750 \mathrm{~km} \mathrm{~s}^{-1}$ purely along the $x$ axis. The constant and purely southward IMF has an intensity of $5 \mathrm{nT}$. The upstream boundary maintains a constant field and a Maxwellian velocity distribution; the three other outer boundaries have copy conditions ensuring proper outflow. The inner boundary, which is set at a distance of $30000 \mathrm{~km}(\sim 5$ Earth radii, $R_{\mathrm{E}}$ ) around the origin, enforces a static Maxwellian velocity distribution and perfect conductor field boundary conditions. The out-of-plane direction is treated periodically. The boundaries are located at $47 R_{\mathrm{E}}$ from the origin in each direction. Since this study concentrates on dayside phenomena, the nightside is not shown in this work. The spatial resolution is $300 \mathrm{~km}$ or $0.047 R_{\mathrm{E}}$ or 1.3 solar wind ion inertial lengths and the velocity space extends from -4000 to $+4000 \mathrm{~km} \mathrm{~s}^{-1}$ in all three dimensions with a resolution of $30 \mathrm{~km} \mathrm{~s}^{-1}$ or 0.33 solar wind ion thermal speeds. The phase space density sparsity threshold is $10^{-15} \mathrm{~m}^{-6} \mathrm{~s}^{3}$ (see von Alfthan et al., 2014, and Kempf et al., 2015, for details on the sparse phase space strategy used in Vlasiator).

The simulation has been run for over $1850 \mathrm{~s}$ or 140 solar wind proton gyroperiods, and it reaches a steady state on the dayside after less than $900 \mathrm{~s}$ or 70 gyroperiods. The bow shock and the magnetopause form as expected and there is a foreshock at high latitudes both in the Northern and Southern hemispheres. The magnetosheath is pervaded by anisotropydriven waves, most notably mirror-mode waves as has been demonstrated by Hoilijoki et al. (2016). Figure 1 shows an overview of the simulation setup after $1150 \mathrm{~s}$ of simulated time. The magnetopause-magnetosheath-bow-shock struc-

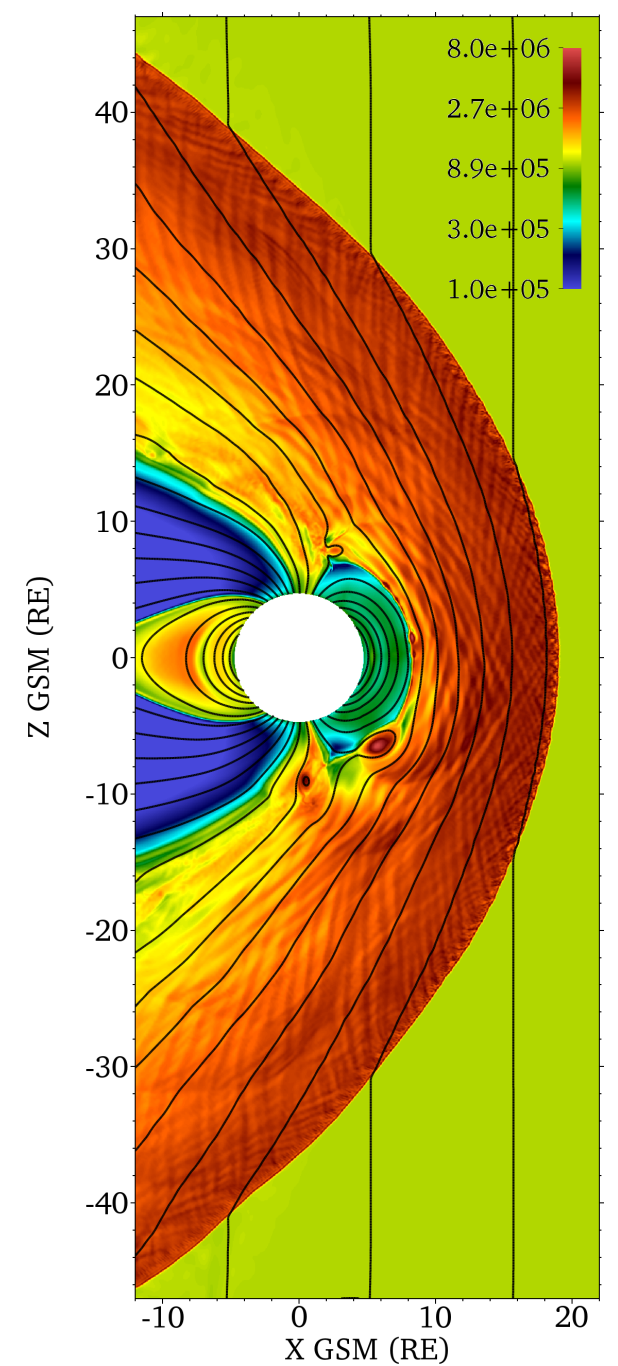

Figure 1. Colour code: plasma number density (protons $\mathrm{m}^{-3}$ ) after 1150 s of simulation time. Contour lines: magnetic field lines. A large magnetic island is prominent at $(+6,-7) R_{\mathrm{E}}$; another one is in the southern cusp region and a series of smaller magnetic islands is visible at the dayside magnetopause northward of the equator.

ture is clear, and a large magnetic island can be recognized due to its high density at the position $(+6,-7) R_{\mathrm{E}}$. A smaller magnetic island is in the southern polar cusp region, while a series of even smaller islands is also visible along the dayside magnetopause boundary northward of the equator. The animation provided in the Supplement to this work shows the time evolution of the ion number density and the parallel temperature for the same spatial extents as Fig. 1 and with the same colour scales as Figs. 1 and 5a.

\subsection{Spacecraft and ground measurements}

We first use solar wind densities, velocities and the IMF one-minute averaged data from NASA/GSFC's OMNI data 
set accessed through CDAweb (Coordinated Data Analysis Web) to identify suitable intervals of stable solar wind and steady southward IMF conditions.

We also use in situ spacecraft measurements from Geotail in this study. The ion velocity distribution measurements are taken from the Low Energy Particle instrument (LEP; Mukai et al., 1994). During the event presented in Sect. 4.3, LEP was in the EA (energy-per-charge analyser) mode, which is not well-suited to properly measure the cold core solar wind ion population but does not impact the quality of suprathermal ion measurements. Editor-B data are available for that event, meaning that only two-dimensional velocity distributions are available. These projected distributions are produced using data from all three-dimensional channels (LEP instrument team, personal communication, 26 August 2016). They are provided in Geocentric Solar Ecliptic (GSE) coordinates $\left(x_{\mathrm{GSE}}\right.$-axis pointing from the Earth towards the Sun, $y_{\mathrm{GSE}}$-axis in the ecliptic plane pointing towards dusk and $z_{\mathrm{GSE}}$-axis perpendicular to the ecliptic plane). Magnetic field measurements are from the Magnetic Field Measurement fluxgate magnetometers (MGF; Kokubun et al., 1994).

The following measurements from the Wind spacecraft are used: solar wind data from its Solar Wind Experiment (SWE; Ogilvie et al., 1995), IMF data from its Magnetic Fields Investigation (MFI; Lepping et al., 1995), moments from its 3-D Plasma and Energetic Particle Analyzer (3-DP; Lin et al., 1995) as well as densities retrieved from the electron plasma frequency measured by the radio and plasma wave instrument (WAVES; Bougeret et al., 1995). The following datasets from the Advanced Composition Explorer (ACE) spacecraft are used: IMF measurements from the Magnetic Fields Experiment (MAG; Smith et al., 1998) and ion moments from the Solar Wind Electron Proton Alpha Monitor (SWEPAM; McComas et al., 1998).

Ground-based ionospheric backscatter data from SuperDARN (Greenwald et al., 1995) as well as ground magnetometer data from the International Monitor for Auroral Geomagnetic Effects (IMAGE, http://space.fmi.fi/image, Tanskanen, 2009) are used. Additionally, we use the electrojet activity auroral electrojet (AE) indices provided by the University of Kyoto through the World Data Center for Geomagnetism (Davis and Sugiura, 1966).

\section{Magnetopause-bow-shock-foreshock interaction scenario}

The scenario proposed in this work has been identified in the simulation presented in Sect. 2.1. We describe the scenario here in Sect. 3 in a narrative fashion and present the corresponding observations in Sect. 4. Limitations are discussed in Sect. 5.
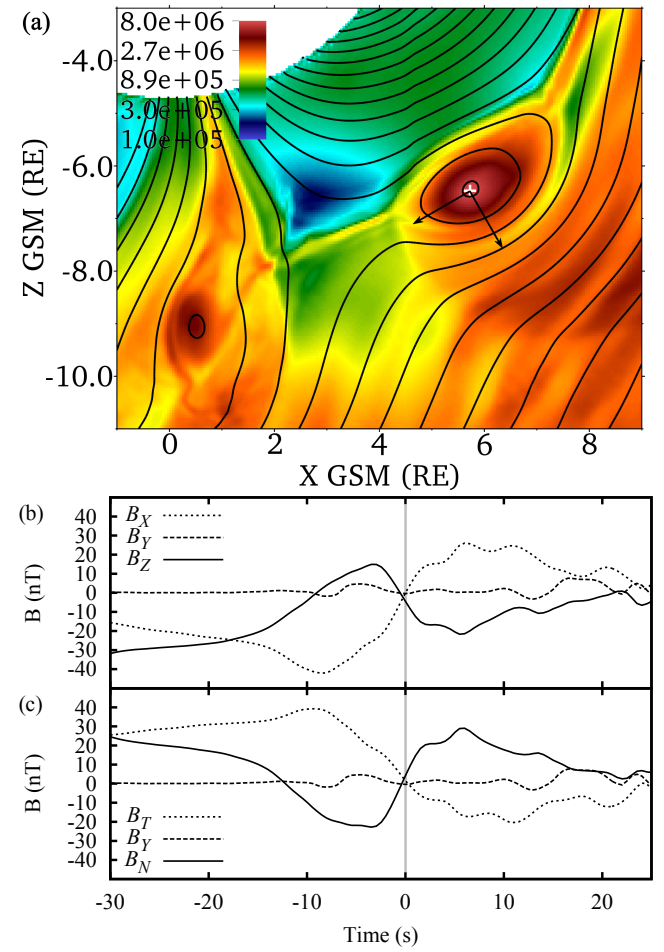

Figure 2. (a) Close-up view of the large magnetic island from Fig. 1 travelling tailward along the magnetopause. Colour code: plasma number density, protons $\mathrm{m}^{-3}$. Contour lines: magnetic field lines. Arrows: rotated coordinate system $(N, Y, T)$ with $N$ normal to the magnetopause and $T$ parallel to it. (b) Magnetic field evolution at a virtual spacecraft located at the white cross in panel (a), in simulation (GSM) and (c) rotated coordinates. The grey vertical bar indicates the time of panel (a) and Fig. 1. The characteristic bipolar signature of the passing magnetic island is obvious in the $\boldsymbol{B}_{N}$ component.

\subsection{Magnetopause reconnection}

Under steady southward IMF, magnetic reconnection occurs typically along a line at the equator on the magnetopause (e.g. Trattner et al., 2007; Dunlop et al., 2011; Hoilijoki et al., 2014). In the present simulation, the position of the $X$-line is not stable in time and multiple reconnection sites can coexist at any given time on the magnetopause. Reconnected field lines form magnetic islands in the exhaust regions of reconnection sites, which grow and travel downstream (poleward) along the magnetopause. This continuously ongoing process is prominent in the animation provided in the Supplement. The magnetic islands can be seen as the two-dimensional equivalents of FTEs, that is, cuts through an out-of-plane flux rope. A more detailed analysis of the propagation of the magnetic islands and the location and intensity of magnetic reconnection is the subject of a separate study.

Figure 2 shows such a magnetic island and time series of the magnetic field components seen at a virtual spacecraft over which the magnetic island flows. The magnetic 

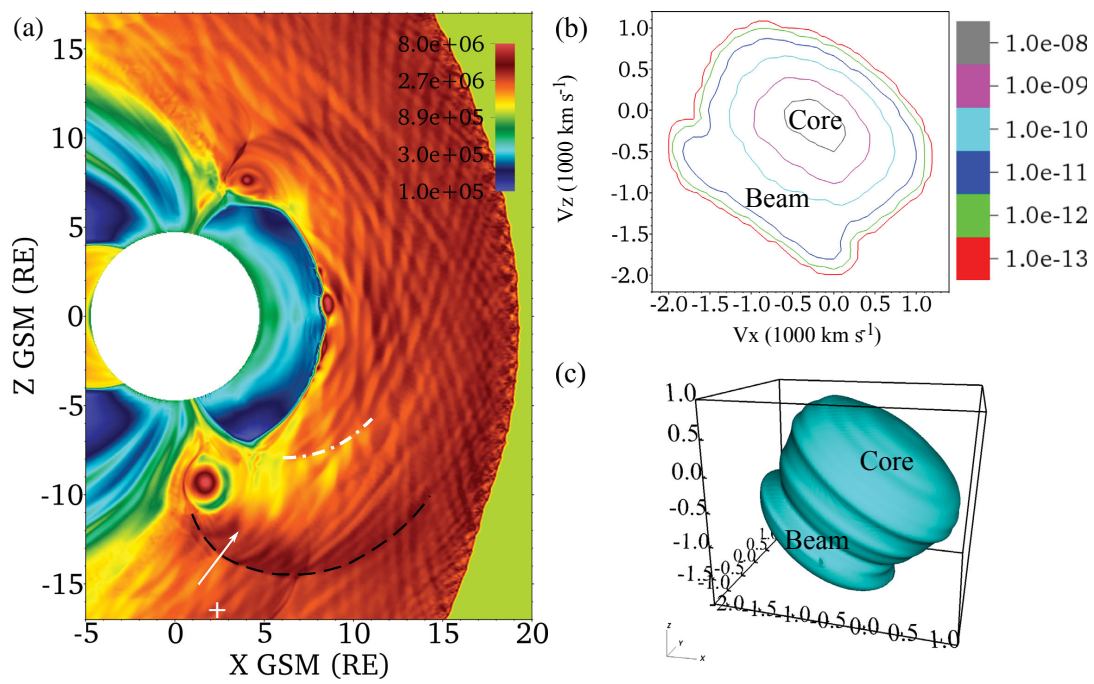

(c)

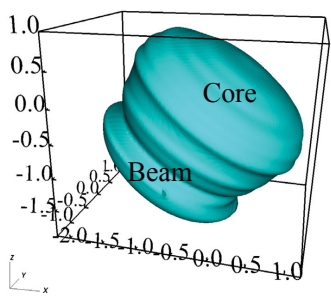

Figure 3. (a) Example of bow (black dashed) and stern (white dash-dotted) fast wave fronts driven by a magnetic island (density peak at $(2,-9) R_{\mathrm{E}}$; colour code: plasma number density; protons $\mathrm{m}^{-3}$; simulation time $\left.1340 \mathrm{~s}\right)$. The bow wave accelerates particles ahead of it, as can be seen in the (b) two-dimensional projected isocontour and (c) three-dimensional isocontour plots of the ion velocity distribution (phase space density in $\mathrm{s}^{3} \mathrm{~m}^{-6}$; 3-D isocontour at $1 \times 10^{-15} \mathrm{~s}^{3} \mathrm{~m}^{-6}$ ) taken at the location of the white cross. The core population with very low drift velocity (blue, pink and grey isocontours, centre and top right part of the 3-D isocontour) is preceded by an accelerated population in the $-V_{x}$ and $-V_{z}$ direction. The white arrow shows the location of the profiles shown in Fig. 4.

field components are shown both in the simulation coordinates and in a coordinate system $(N, Y, T)$ rotated by $150^{\circ}$ in the plane of the simulation so that $N$ points in the direction normal to the magnetopause and $T$ points along the magnetopause. The strong bipolar fluctuation in the $\boldsymbol{B}_{N}$ component is characteristic of the passage of a magnetic island.

\subsection{Magnetosheath waves and bow shock perturbations}

Figure 3a shows a magnetic island in the southern cusp region. The increased dynamic pressure of the magnetic islands with respect to the surrounding magnetosheath plasma drives bow waves ahead of the islands. These fast magnetosonic waves propagate throughout the magnetosheath and steepen to almost form fast forward shocks. In some cases, strong magnetic islands can also be followed by a fast reverse wave front, but these stern waves are less steep than the bow wave fronts. Both the bow and stern fast mode waves are visible in Fig. 3a. The profiles of plasma density, velocity and temperature perpendicular to the magnetic field as well as the magnetic field intensity show clearly the steep correlated increase corresponding to the fast forward wave front in Fig. 4a-d. The forward wave fronts are steep enough to reflect ions much in the way a shock can accelerate ions to generate upstream foreshock populations. Figure $3 \mathrm{~b}$ and $\mathrm{c}$ shows the two- and three-dimensional velocity distribution function isocontours at the location of the white cross in Fig. 3a. The accelerated ions are clearly visible ahead of the core population in the $-V_{x}$ and $-V_{z}$ direction. The structure is also readily visible in the profile of the temperature parallel to the

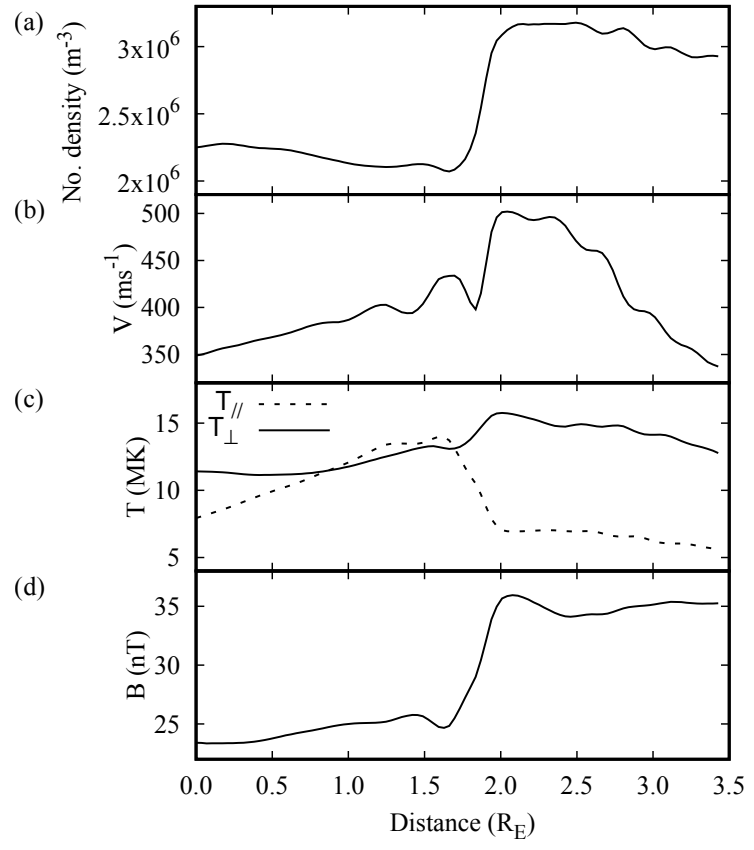

Figure 4. Cut across the bow wave front along the white arrow in Fig. 3 showing (a) the plasma density and (b) velocity, (c) the temperature parallel and perpendicular to the magnetic field, and (d) the magnetic field intensity. The correlated jump in all these parameters at the abscissa $2 R_{\mathrm{E}}$ characterizes the steep fast forward wave front. Note the fast wave signature in the perpendicular temperature while the parallel temperature is much more sensitive to the particle beam accelerated ahead of the wave front. 

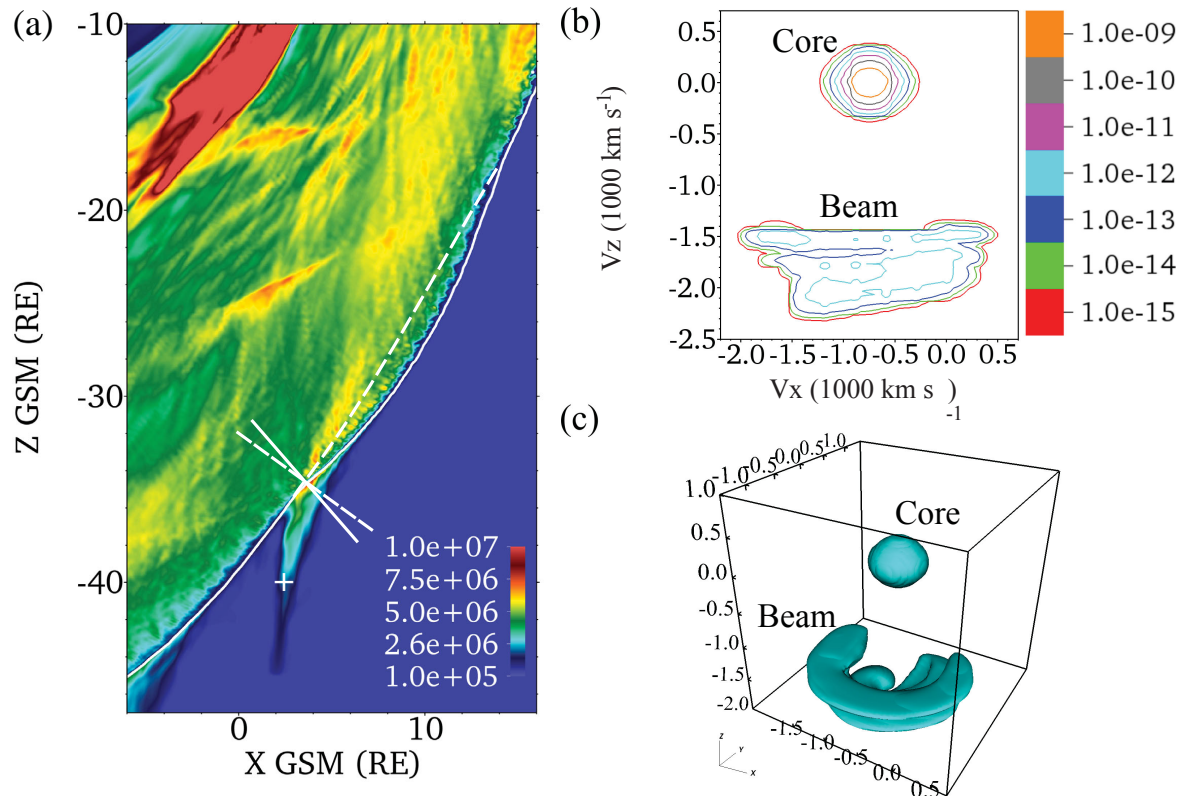

Figure 5. (a) Colour code: temperature $(\mathrm{K})$ parallel to the magnetic field in a region presenting a local foreshock at $1548.5 \mathrm{~s}$ simulation time. This variable is sensitive to the presence of an ion beam, hence the choice to bring out the local foreshock. The continuous white isocontour curve shows where the ion density is $2 \times 10^{6} \mathrm{~m}^{-3}$ (twice the solar wind density), thus indicating the bow shock location. The dashed white curve would show the approximate position of the bow shock were it not for the increased pressure due to a fast wave front in the magnetosheath. The continuous and dashed segments indicate the normal direction for each of these curves. $\theta_{\boldsymbol{B}-\boldsymbol{n}}: 41^{\circ}$ and $54^{\circ}$; thus the angle between both is $13^{\circ}$. (b) Two-dimensional projected isocontour and (c) three-dimensional isocontour plots of the ion velocity distribution (phase space density in $\mathrm{s}^{3} \mathrm{~m}^{-6}$; 3-D isocontour at $1 \times 10^{-15} \mathrm{~s}^{3} \mathrm{~m}^{-6}$ ) at the location of the white cross. The field-aligned beam is prominent and directly comparable to Figs. 2 and 6 in the work by Kempf et al. (2015).

magnetic field in Fig. 4c; the steep increase in the parallel temperature from 7 to $14 \mathrm{MK}$ is the direct signature of the presence of an accelerated ion population upstream of the wave front in addition to the background magnetosheath ion population. The increased parallel temperature ahead of the wave fronts is visible too in the right panel of the animation provided in the Supplement.

Downstream of the fast magnetosonic waves, the magnetosheath plasma has higher thermal, dynamic and magnetic pressure. The straightforward consequence of this phenomenon is - considering the pressure balance when the wave fronts reach the bow shock - that the bow shock is pushed outwards against the solar wind, forming a localized bulge corresponding to the region of enhanced magnetosheath pressure.

\subsection{Local foreshocks}

Figure 5a shows the detailed view of a small region of the bow shock south of the subsolar point. When the angle between the shock normal and the upstream magnetic field $\theta_{\boldsymbol{B}-\boldsymbol{n}}$ is lower than $\sim 50^{\circ}$, incoming particles with sufficient energy can be accelerated back upstream and form a foreshock. Consequently, when the bow shock bulge caused by the fast-wave-mediated pressure increase is pronounced enough, the region of the bulge with $\theta_{\boldsymbol{B}-\boldsymbol{n}} \lesssim 50^{\circ}$ is the source of a separate ion beam propagating upstream along the IMF direction. This is of course only the case when the bulge has not yet travelled into the region where the mean $\theta_{\boldsymbol{B}-\boldsymbol{n}}$ is allowing ion reflection anyway. The spatial extent in the direction parallel to the bow shock surface is limited to the corresponding patch of favourable $\theta_{\boldsymbol{B}-\boldsymbol{n}}$, and this localized foreshock travels along with the driving magnetosheath wave front until it merges with the regular foreshock further downstream. Due to its being a travelling and transient ion beam, the expected beam instabilities do not have time to grow to form ultra low-frequency (ULF) waves as in the regular foreshock (see, e.g., von Alfthan et al., 2014; Palmroth et al., 2015). This means that the typical ULF wave signature characteristic of the regular foreshock is absent from this structure.

Figure 5a shows an example of a localized foreshock driven by a magnetosheath wave. The colour code in the figure shows the temperature parallel to the magnetic field, which is sensitive to the presence of a field-aligned ion beam. The white contour curve is set at a plasma density of $2 \times 10^{6} \mathrm{~m}^{-3}$ (twice the solar wind density), which highlights the position and shape of the bow shock. The dashed curve would indicate the approximate location of the bow shock were it not for the pressure increase in the magnetosheath 


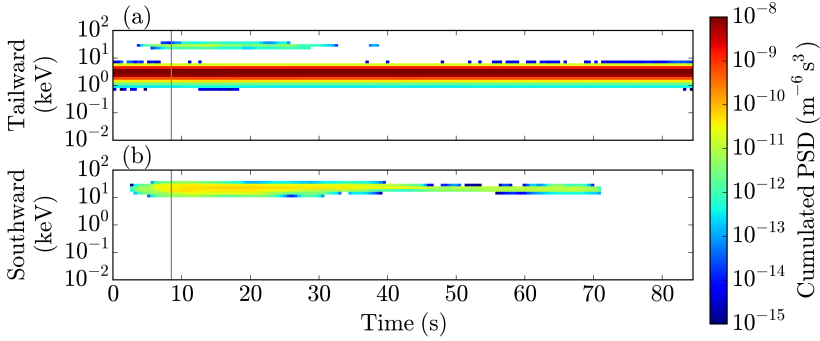

Figure 6. Energy-time spectrogram of the simulated local foreshock crossing event at the location marked in Fig. 5. The grey vertical bar indicates the time of Fig. 5. The velocity distribution has been split into four sectors (sunward, southward, tailward and northward in the simulation/polar plane, $\pm 45^{\circ}$ from the $+x,-z$, $-x$ and $+z$ direction respectively), two of which are plotted here. (a) The dense tailward population at an energy of a few kiloelectronvolt is the solar wind core. (b) The local foreshock beam forms the population at a few tens of kiloelectronvolt in the southward sector and lasts almost $70 \mathrm{~s}$. Thus the expected observational signature is that of a field-aligned beam with a duration of the order of $1 \mathrm{~min}$.

after the passage of a fast forward wave front. The continuous and dashed segments indicate the local direction normal to the respective curve. Their $\theta_{\boldsymbol{B}-\boldsymbol{n}}$ is respectively $41^{\circ}$ and $54^{\circ}$. The ion beam is generated by solar wind ions reflected at the foot of the bow shock bulge where $\theta_{\boldsymbol{B}-\boldsymbol{n}}$ is favourable. Beyond $-3 R_{\mathrm{E}}\left(x_{\mathrm{GSM}}\right)$, the regular foreshock is also visible upstream of the bow shock as a region of increased parallel temperature. The fact that the density and parallel temperature increases due to the bow shock do not coincide, illustrates that the shock primarily heats plasma in the perpendicular direction. Isotropization of the velocity distribution happens further downstream in the magnetosheath.

The animation provided in the Supplement to this work shows that such local foreshocks occur both north and south of the ecliptic whenever favourable $\theta_{\boldsymbol{B}-\boldsymbol{n}}$ conditions are met at the foot of a bow shock perturbation.

Figure $5 \mathrm{~b}-\mathrm{c}$ shows the ion velocity distribution function corresponding to a field-aligned beam population, which is similar to the distribution expected at the edge of the regular foreshock upstream of the ULF foreshock boundary (Kempf et al., 2015). The density of the beam is of the order of $1 \%$ of the inflowing density as in the regular foreshock (not shown). Figure 6 shows an energy-time spectrogram for the tailward and southward sectors of the velocity distribution. The tailward part contains the cold solar wind core population, while the southward sector, in the direction of the field-aligned beam, indicates the typical signature expected when a local foreshock crosses an upstream spacecraft. The timescale of a local foreshock crossing is on the order of $1 \mathrm{~min}$ in the simulation (almost $70 \mathrm{~s}$ in Fig. 6), but this value can vary depending on the geometry of the event. Other factors affecting the observational signatures are discussed in Sect. 5.

\section{Spacecraft and ground observations}

In Sect. 3 we present a scenario based on a global hybridVlasov simulation, in which dayside reconnection eventually leads to the formation of local, transient foreshock-like structures upstream of the terrestrial bow shock and outside of the region where the angle between the shock normal and the IMF $\left(\theta_{\boldsymbol{B}-\boldsymbol{n}}\right)$ would normally be favourable for ion reflection. In this section, we present observational data from an event on 30 August 2004 which supports the interpretation of the simulation. While Geotail observed transient field-aligned ion beams in the solar wind upstream of the bow shock and the foreshock between 08:09 and 08:24 UT, ground-based SuperDARN radar data and IMAGE magnetometer data indicate that dayside reconnection was active and producing FTEs.

\subsection{Upstream pristine solar wind conditions}

The OMNI data set (from ACE) containing the upstream magnetic field, ion velocity, ion density and ion temperature on 30 August 2004 is plotted in Fig. 7. It shows that the IMF turned south at about 05:00 UT and $\boldsymbol{B}_{z}$ remained strongly negative around $-10 \mathrm{nT}$ for most of the day until about 22:00 UT. The velocity and temperature of the solar wind remained stable around $480-490 \mathrm{~km} \mathrm{~s}^{-1}$ and $10^{4} \mathrm{~K}$ respectively between 08:00 and 19:00 UT, while $\boldsymbol{B}_{z}$ slowly decreased from -8 to $-11 \mathrm{nT}$ and the density slowly increased from about 5 to $10 \mathrm{~cm}^{-3}$.

\subsection{Ground observations}

The strong southward $\boldsymbol{B}_{z}$ component of the IMF is the cause of strong magnetic reconnection at the dayside magnetopause, which in turn is known to produce numerous FTEs (e.g. Kawano and Russell, 1997). Global activity indices clearly indicate ongoing magnetic reconnection during the event. The prolonged period of southward IMF triggered a geomagnetic storm and the increased levels of magnetic reconnection both on the dayside and the nightside are reflected in the AE indices, which started picking up between 05:00 and 06:00 UT and reached levels above $\mathrm{AE}=500 \mathrm{nT}$ after 08:00 UT.

Evidence for continuous FTE activity during the period 06:00 to 10:00 UT is observed by two SuperDARN radars in the Southern Hemisphere, presented in Fig. 8. The Kerguelen and Syowa East radars were observing backscatter from the pre-noon and noon region during this period. Figure $8 \mathrm{a}-\mathrm{c}$ show the Kerguelen line-of-sight velocity data at 07:08, 07:32 and 08:22 UT. Three regions of backscatter are labelled A to C. In the polar cap (A), $1 \mathrm{~km} \mathrm{~s}^{-1}$ flows away from the radar (antisunwards) are observed, $700 \mathrm{~m} \mathrm{~s}^{-1}$ flows away from the radar (polewards) are seen entering the polar cap near noon (B), and $700 \mathrm{~ms}^{-1}$ flows towards the radar (sunwards) are seen in the return flow region (C). As the 

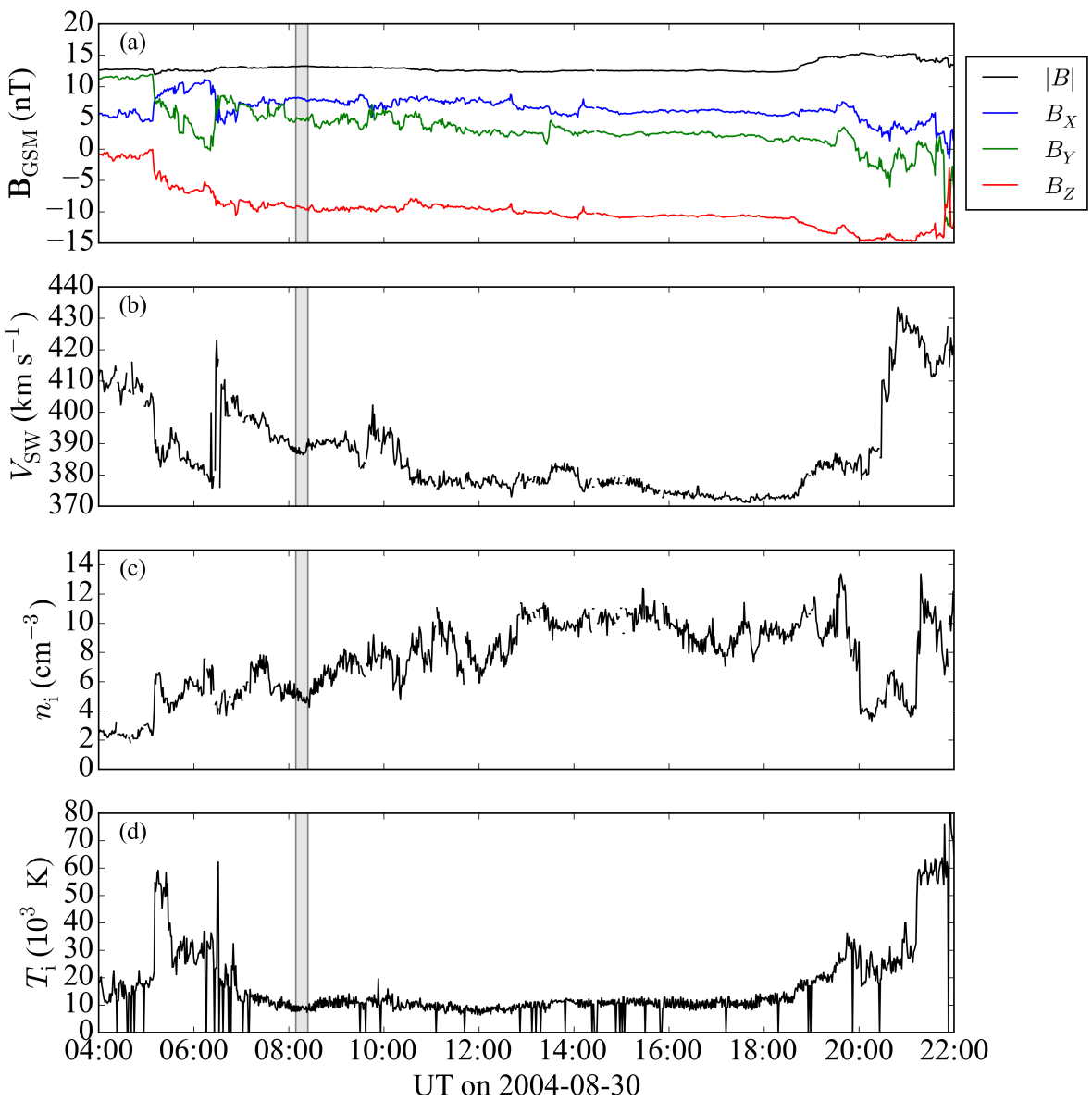

Figure 7. Upstream solar wind observations between 04:00 and 22:00 UT on 30 August 2004, from the OMNI dataset with 1 min time resolution. (a) Magnetic field. (b) Velocity. (c) Ion number density. (d) Ion temperature. The grey box shows the interval of the event presented in Fig. 11 and Sect. 4.3.

Earth rotates the look direction of the radar changes, but these backscatter regions continue to be observed. Rangetime plots show that these backscatter regions are quasiperiodically pulsed with periods near $10-15 \mathrm{~min}$, the expected signature of pulsed reconnection (e.g. Provan et al., 1998; Milan et al., 1999a, 2000; Wild et al., 2001). This is seen as poleward-moving enhancements in the backscatter power in the polar cap flows of region A in Fig. 8f. It is also observed as pulses of backscatter and flow in the return flow region, as first discussed by Milan et al. (1999b), that is, pulsed flows observed moving towards the Kerguelen radar (i.e. sunwards) in the return flow backscatter region $\mathrm{C}$ (Fig. 8e) and pulsing moving away from the Syowa East radar (also sunwards), in backscatter collocated with region C (Fig. 8i).

IMAGE magnetometers also observed signatures that could be interpreted as FTE activity. Figure 9a shows the ionospheric equivalent current density at $110 \mathrm{~km}$ altitude in the Northern Hemisphere at 08:15 UT. The equivalent current density was derived from 10s IMAGE magnetometer data using spherical elementary current systems (SECS; Amm, 1997; Amm and Viljanen, 1999). Before applying the SECS method, a baseline was subtracted from the variometer data following van de Kamp (2013). The $J_{\mathrm{eq}}$ data are presented as a function of Altitude Adjusted Corrected Geogmagnetic Coordinates (AACGM; Shepherd, 2014) latitude and longitude, which at the given UT correspond to 09:05-11:09 magnetic local time (MLT). The plot has been rotated such that local noon is at the top. The plot shows eastward and equatorward equivalent current density vectors in the poleward part of the IMAGE field of view. If gradients of the ionospheric conductances are vanishingly small or aligned with the electric field in a large enough area, the equivalent current equals the Hall current, which flows antiparallel to the ionospheric $\boldsymbol{E} \times \boldsymbol{B}$ drift. According to Weygand et al. (2012), this is often a good approximation. Thus, the equatorward equivalent current in Fig. 9a may indicate poleward plasma flow entering the polar cap.

Figure 9b shows a $\left|J_{\text {eq }}\right|$ keogram, that is, latitude profiles of $\left|J_{\text {eq }}\right|$ along $105^{\circ}$ longitude presented as a function of time 



Figure 8. (a-c) Line-of-sight velocities (blue towards the radar, red away from the radar) from the Kerguelen SuperDARN radar in the Southern Hemisphere, at 07:08, 07:32 and 08:22 UT. Grey regions are ground scatter. The data are presented in geomagnetic latitude and magnetic local time coordinates, with dotted circles indicating geomagnetic latitudes of 60,70 and $80^{\circ}$ and dotted lines showing local time meridians with local noon at the top. The outline of the radar field of view is shown by dashed lines, as is the field of view of the Syowa East radar. Grey circles indicated the expected locations of the poleward and equatorward edges of the auroral oval. Three regions of backscatter are indicated by the letters A, B and C. (d-i) Backscatter power and line-of-sight velocity from beams 0 and 13 of the Kerguelen radar and beam 9 of the Syowa East radar. Regions of backscatter are also labelled A to C.

between 06:00 and 10:00 UT. The vertical lines indicate the interval 08:09-08:24 UT during which Geotail observed the ion beam signature. The occurrence of the $\left|J_{\text {eq }}\right|$ intensifications observed by IMAGE between 70 and $75^{\circ}$ latitude before about 09:00 UT roughly agrees in time with the Southern Hemisphere FTE signatures observed by SuperDARN.
One of the intensifications occurred during the interval when Geotail observed the ion beam signature.

\subsection{Geotail observations}

On 30 August 2004, Geotail was located on the dayside of the Earth and upstream of the bow shock in the solar wind. Between about 08:00 and 08:30 UT, Geotail was 
30 Aug 2004 08:15:00 UT (09:05-11:09 MLT)
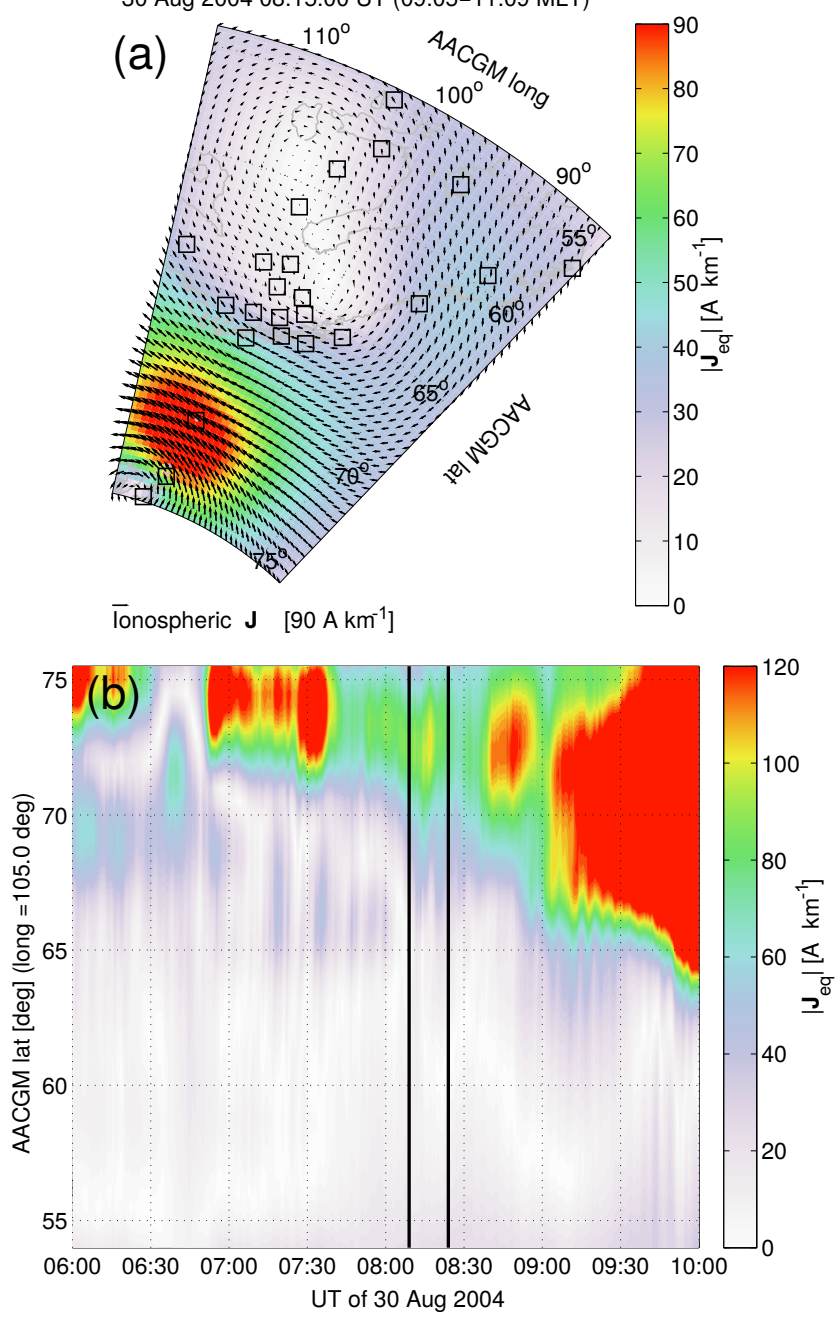

Figure 9. (a) Ionospheric equivalent current density at $110 \mathrm{~km}$ altitude ( $J_{\text {eq }}$, arrows; $\left|J_{\text {eq }}\right|$, colour) in the Northern Hemisphere on 30 August 2004 at 08:15 UT, derived from 10s IMAGE magnetometer (squares) data. The data are presented as a function of geomagnetic (AACGM) latitude and longitude, which at the given time correspond to 09:05-11:09 MLT. The plot has been rotated such that local noon is at the top. (b) $\left|J_{\text {eq }}\right|$ keogram (latitude profiles along $105^{\circ}$ longitude presented as a function of time between 06:00 and 10:00 UT). The vertical lines indicate the interval (08:09-08:24 UT) during which Geotail observed the ion beam signature.

located at $(17.6,23.0,-9.2) R_{\mathrm{E}}$ in GSM coordinates and $(17.6,24.5,3.6) R_{\mathrm{E}}$ in GSE coordinates. The location of Geotail with respect to a model bow shock and ion foreshock edge is shown in Fig. 10 (details of the bow shock and foreshock models are given in Sect. 5.1). Geotail/MGF observed stable IMF with $\boldsymbol{B}_{\mathrm{GSM}}=(7,5,-9) \mathrm{nT}$, as shown in Fig. 11c. No perturbations of the magnetic field are seen which would modify its orientation, thus altering the magnetic connection to the bow shock and the location of the foreshock. Smallamplitude regular fluctuations are visible throughout, which (a)

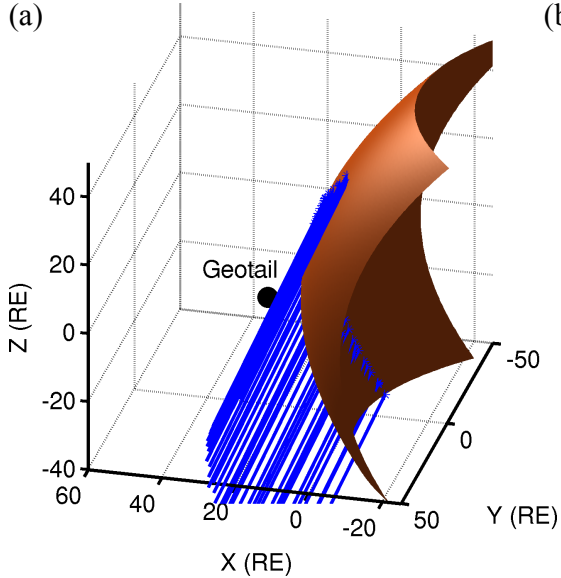

(b)

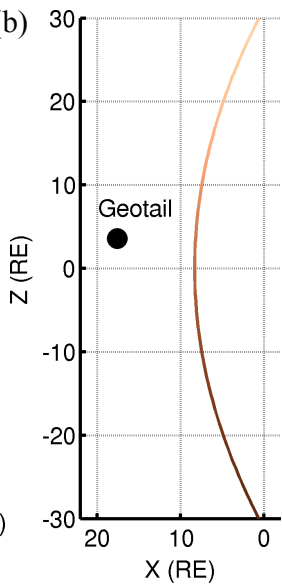

Figure 10. (a) Plot showing the location of Geotail at 08:16:10 UT on 30 August 2004 with respect to the bow shock following the model by Merka et al. (2005) and the foreshock edge assuming that the maximum $\theta_{\boldsymbol{B}-\boldsymbol{n}}$ for ion reflection is $60^{\circ}$ and the reflected ions have twice the solar wind speed (in the solar wind frame). (b) $x-z$ slice at the $y$ coordinate of Geotail showing the spacecraft and the bow shock location. (Plots in GSE coordinates.)

coincide with Geotail's nominal spin rate of $20 \mathrm{rpm}$. They are therefore likely a residual from the data calibration process.

The energy-time spectrograms from the Geotail/LEP instrument for the ions flying in the tailward and duskward directions are shown in Fig. 11a and b. Only two-dimensional projected ion velocity distributions in the ecliptic plane are available from LEP for this event, hence the choice of sectors. The tailward sector is dominated by the steady cold and dense solar wind core population just below $1 \mathrm{keV}$. Between about 08:09 and 08:24 UT (time delimited by the black dotted lines in Fig. 11) the duskward sector exhibits several occurrences of an ion population at energies of a few kiloelectronvolt reminiscent of the signature of foreshock fieldaligned beam ions. The presence of a beam in this sector is consistent with the significant $\boldsymbol{B}_{y}$ component of the IMF.

In contrast to regular foreshock field-aligned beams, this beam is transient and appears several times after 08:10 UT for one to a few minutes without correlation with changes in the magnetic field direction, as can be seen by comparing panels a-c in Fig. 11. Panel d shows the velocity and number density of the ions from the OMNI data set with a 1 min time resolution. The velocity is stable and varies only by about $1 \%$, while the density fluctuates between 4.5 and $5.5 \mathrm{~cm}^{-3}$ but without correlating with the transient beam event. We choose the OMNI density and velocity data because the densities reported by Geotail/LEP do not seem to be consistent. This is likely due to the fact that LEP is in EA mode and not in SW (solar wind analyser) mode, which would have ensured a better measurement of the solar wind core population. To ensure that the choice of the OMNI data is sensible, we compare shifted ACE and Wind magnetic field mea- 


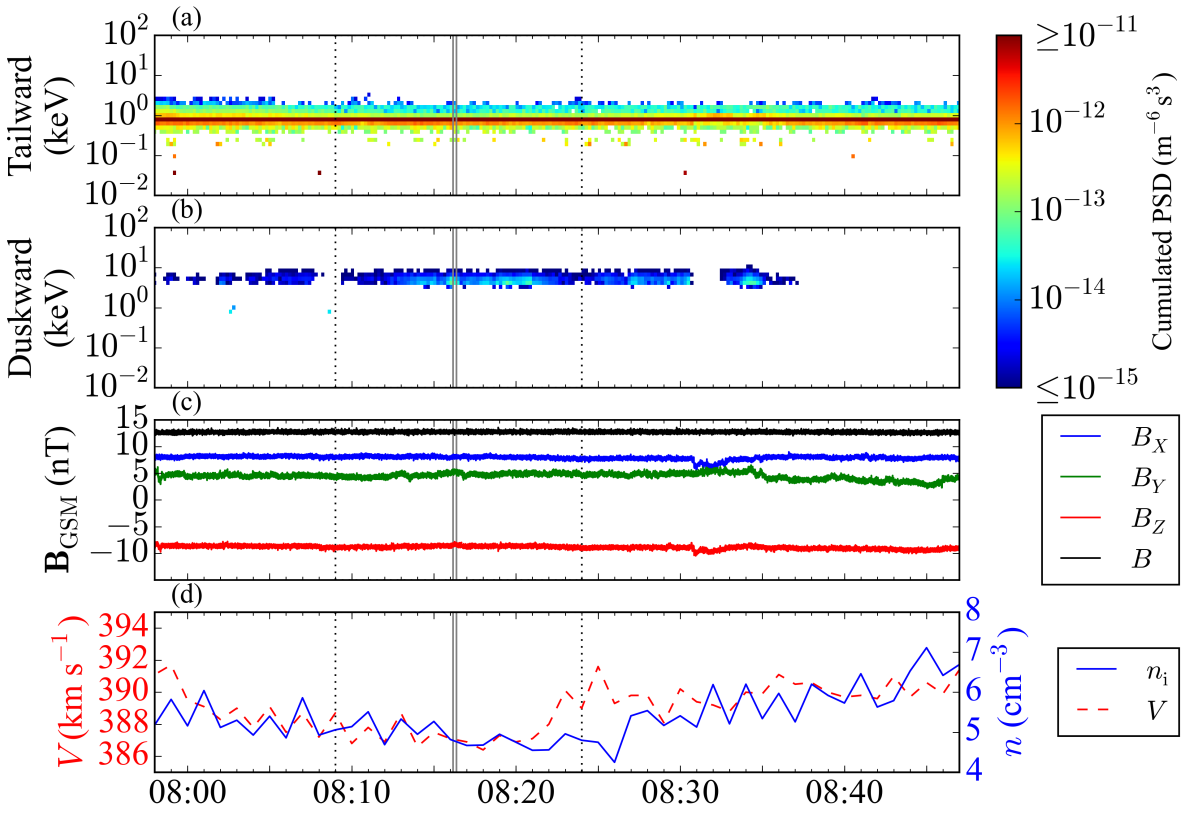

Figure 11. Geotail/LEP energy-time spectrogram on 30 August 2004 between 07:48 and 08:47 UT, for the (a) tailward and (b) duskward sectors $\left( \pm 45^{\circ}\right.$ from the $+x$ and $+y$ direction respectively), extracted from the two-dimensional reduced velocity distribution in the GSE ecliptic plane. The tailward sector shows the cold and dense solar wind core population just below $1 \mathrm{keV}$. The duskward sector shows the signature of a transient beam whose density peaks several times between 08:09 and 08:24 UT (time delimited by the black dotted lines). (c) Geotail/MGF magnetic field in GSM coordinates. The magnetic field components and thus its orientation are stable during the event. The short-period oscillations coincide with Geotail's nominal spin rate of $20 \mathrm{rpm}$. (d) OMNI plasma number density and velocity. The grey continuous bars indicate the time at which the velocity distribution shown in Fig. 12 is measured.

surements to the Geotail/MGF data to check that the OMNI propagation algorithm is successful. We then check that the densities and velocities from ACE and Wind are similar to each other and to the OMNI dataset. Since this is the case and the OMNI values are similarly stable to the ACE (which was used to produce the OMNI dataset) and Wind data at a higher time resolution, we conclude that the OMNI dataset is reliable and sufficient here. LEP being in EA mode instead of SW affects the quality of the measurement for the core population but not for the beam, which is of prime interest here.

Figure 12 shows the projected two-dimensional velocity distribution in the $V_{x}-V_{y}$ GSE plane measured by the Geotail/LEP between 08:16:10 and 08:16:22 UT (time delimited by the grey continuous bars in Fig. 11). The solar wind core population is prominent in the lower left at $V_{x} \sim-400 \mathrm{~km} \mathrm{~s}^{-1}$, while a typical field-aligned beam flows back upstream along the magnetic field with positive $V_{x}$ and $V_{y}$ components. The black arrow points in the average direction of the magnetic field in the $x-y$ GSE plane during the time interval, and the grey dots indicate all measurements taken at an $8 \mathrm{~Hz}$ cadence by the MGF instrument during the same time. Their close grouping once more indicates the stability of the magnetic field direction.

It is worth noting that while exactly similar magnetic field and solar wind conditions prevail in the $10 \mathrm{~min}$ pre- ceding the event, no such field-aligned beam is seen before 08:10 UT. Additional ion beams are visible between 08:24 and 08:40 UT, but in their case the influence of magnetic field perturbations observed simultaneously cannot be conclusively ruled out.

\section{Discussion}

In Sect. 4 we present Geotail observations of transient fieldaligned ion beams upstream of the Earth's bow shock, while ground-based SuperDARN radar data and IMAGE magnetometer data show that pulsed dayside reconnection producing FTEs was occurring at the same time. This matches the observational signatures expected from the scenario drawn in Sect. 3 based on a global magnetospheric simulation. In this Sect. 5 we first investigate the position of Geotail with respect to the regular foreshock, and we then discuss the more general factors which might affect the interpretation of the simulation and the measurements.

\subsection{Position of Geotail relative to the regular foreshock}

It is important to ascertain that Geotail is not too close to the bow shock or to the foreshock. Indeed if it were in the vicinity of either, it could observe for example shock foot ion populations or the edge of field-aligned beam populations 


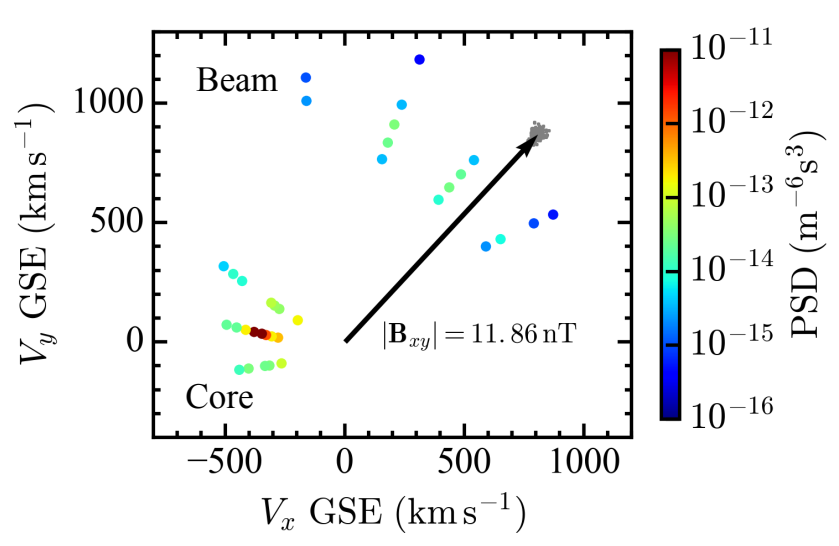

Figure 12. Coloured dots: Two-dimensional reduced ion velocity distribution in GSE coordinates measured by Geotail/LEP between 08:16:10 and 08:16:22 UT. The cold solar wind core flows with $V_{x} \sim-400 \mathrm{~km} \mathrm{~s}^{-1}$, and the hotter field-aligned beam propagates in the opposite direction. Black arrow: averaged magnetic field direction in the $x-y$ GSE plane measured by Geotail/MGF during the interval. Grey dots: all individual Geotail/MGF measurements taken at $8 \mathrm{~Hz}$ cadence. The stability of the orientation of the magnetic field is remarkable.

from the foreshock, which would look very similar to the signature expected from a local foreshock.

We use the bow shock model from Merka et al. (2005) with the OMNI solar wind parameters and the Geotail/MGF observed magnetic field as inputs to determine the expected bow shock shape and position. As a first approach we determine the position of the expected ion foreshock edge. We trace the observed magnetic field to find the locus on the bow shock surface where $\theta_{\boldsymbol{B}-\boldsymbol{n}}=60^{\circ}$, and then we trace the trajectories of ions reflected from there with twice the solar wind inflow speed in the solar wind rest frame. This is typical of field-aligned beams in the foreshock (e.g. Greenstadt et al., 1980; Eastwood et al., 2005a; Kis et al., 2007). From this modelling we determine that Geotail is $3-5 R_{\mathrm{E}}$ away from the foreshock edge and $9-10 R_{\mathrm{E}}$ clear of the bow shock during the event between 08:09 and 08:24 UT, whence we could conclude that the spacecraft is well beyond reach of bow shock foot or foreshock edge ions. The result of this analysis is what is presented in Fig. 10.

However, as can readily be estimated from the observed velocity distribution shown in Fig. 12, the beam is significantly faster in the solar wind rest frame than twice the solar wind inflow velocity in the spacecraft frame. To get a better estimate of whether Geotail is within reach of the regular foreshock, we consider the trajectory of foreshock ions assuming adiabatic reflection at the bow shock (Schwartz et al., 1983; Liu et al., 2016). Adiabatic reflection and not specular reflection is assumed because it yields higher beam speeds and would thus be more likely to reach the spacecraft. Incoming ions at velocity $\boldsymbol{V}$ impinge on the bow shock, which has a local normal vector $\boldsymbol{n}$, and are reflected with a velocity

$\boldsymbol{V}_{\mathrm{r}}=-\boldsymbol{V}+2 \boldsymbol{V}_{\mathrm{HT}}$,

where

$\boldsymbol{V}_{\mathrm{HT}}=\frac{\boldsymbol{n} \times(\boldsymbol{V} \times \boldsymbol{B})}{\boldsymbol{n} \cdot \boldsymbol{B}}$

is the de Hoffmann-Teller velocity of the bow shock (De Hoffmann and Teller, 1950) and $\boldsymbol{B}$ is the IMF.

The validity of the assumption that ions are reflected adiabatically can be checked against the simulation. In Fig. 5a we have $\theta_{\boldsymbol{B}-\boldsymbol{n}}=41^{\circ}$ at the foot of the local foreshock, the solar wind velocity is $-750 \mathrm{~km} \mathrm{~s}^{-1}$ purely along the $x$ axis, and the IMF is constant and purely southward at $5 \mathrm{nT}$. With those parameters, Eqs. (1) and (2) yield $\boldsymbol{V}_{\mathrm{r}}^{\mathrm{sim}}=$ $(-750,0,1725.6) \mathrm{km} \mathrm{s}^{-1}$. This does indeed correspond to the beam velocity as shown by the projected velocity distribution function in Fig. 5b, confirming the assumed adiabatic reflection process.

To check whether Geotail observed adiabatically reflected ions from the regular foreshock, we trace the observed beam from Geotail back to the bow shock along the IMF direction and invert Eq. (1) to reconstruct the solar wind velocity vector $V^{\prime}$ that would yield the measured beam velocity with the assumed model bow shock. For the observed beam (Fig. 12), the resulting solar wind velocity vector would have the components $V^{\prime}=(-557,-602,317) \mathrm{km} \mathrm{s}^{-1}$ in GSE coordinates, which is obviously not in accordance with the observed solar wind (Figs. $7 \mathrm{~b}$ and 11d). Having thus ascertained that in these solar wind and IMF conditions the observed beam cannot have been reflected adiabatically from the modelled bow shock, we perturb the model bow shock until the adiabatically reflected ion trajectory matches the observed beam. When $\boldsymbol{n}$ is rotated towards $\boldsymbol{B}$ by an angle of $15^{\circ}$, the adiabatically reflected ion beam does indeed hit Geotail. This value is remarkably close to the angle of $13^{\circ}$ between the unperturbed and perturbed bow shock normals at the foot of the local foreshock in the global simulation (Fig. 5a). It has to be noted though that the beam velocities obtained with this approach do not agree well with the observed ones (reconstructed velocity $688 \mathrm{~km} \mathrm{~s}^{-1}$, observed velocity $885 \mathrm{~km} \mathrm{~s}^{-1}$ in the spacecraft frame), which means that the reflection and acceleration process and their geometry are probably more complex than the simple adiabatic reflection we assume here.

In summary this analysis demonstrates that Geotail is out of reach for adiabatically reflected field-aligned beam ions originating from the unperturbed foreshock under the prevailing solar wind and IMF conditions. By introducing an ad hoc local perturbation of the bow shock normal of $15^{\circ}$, we recover a beam direction consistent with the Geotail observations, which is similar to the bow shock perturbation seen in the global simulation. 


\subsection{Estimating the propagation direction of the perturbation}

Assuming that three-dimensional velocity distribution measurements were available with a high cadence, it would be possible to estimate the direction and speed of propagation of the field-aligned ion beam. Indeed at the edge of an ion beam, non-gyrotropic partial ring or beam distributions are observed in a region of one gyrodiameter width (e.g. Schwartz et al., 2000; Kempf et al., 2015). Timing the transition from a partial to a full gyrotropic beam and back on each side of the beam passage across the spacecraft yields an approximate beam propagation speed since the gyrodiameter of the ions is known. Furthermore, the gyrophase of the ions at the very edge of the beam indicates on which side of the spacecraft the beam is located, so that the incoming and outgoing edges yield an estimate of the beam edge orientation. However the lack of knowledge of the shape of the beam complicates the matter to some extent. For the event presented in Sect. 4, such estimates are not feasible with the Geotail data available and the comparison of the event timings in the absence of a more detailed knowledge of the shape of the bow shock perturbation and beam is of no use.

\subsection{Simulation model limitations}

The main limitation of the simulation presented is its twodimensionality. Due to this configuration, all inflowing magnetic flux is forced to reconnect at the magnetopause and cannot flow past without reconnecting, unlike in three dimensions. This forces magnetic reconnection to be strong and occur all the time at the magnetopause. Further, this likely means that the magnetic islands carry more momentum and thus drive stronger bow and stern waves into the magnetosheath than they would in three dimensions.

Additionally, the steady solar wind conditions in the simulation preclude any upstream turbulence, yielding a smooth bow shock and no more downstream turbulence than the anisotropy-driven wave activity in the magnetosheath. Therefore the magnetic-island-driven fast waves can propagate relatively unhindered in the magnetosheath and the localized field-aligned beam is also very prominent in the solar wind. More realistic turbulent conditions would certainly yield less conspicuous signatures.

Nevertheless, none of these limitations mean that the fully three-dimensional and turbulent case could not exhibit transient local foreshocks, they might only be more difficult to detect and distinguish from other sources of bow shock and foreshock perturbations or ion beams.

\subsection{Observational limitations}

The long chain of phenomena from the magnetopause through the magnetosheath and bow shock to the foreshock, constituting the scenario presented in this work, makes it daunting to observe the whole cascade of a single event in space and time. This would require the fortuitous availability of adequate measurement data firstly at the magnetopause to identify FTEs, secondly in the magnetosheath to single out steepened fast wave fronts, and thirdly upstream in a narrow region close to but definitively more than one ion gyroradius away form both the bow shock foot and the regular foreshock edge, all of this during a stable southward IMF stretch and in the absence of any magnetic field fluctuations which could either drive an ion beam or produce a regular foreshock crossing at the upstream spacecraft instead. No suitable spacecraft were located in the magnetosheath or at the magnetopause during the Geotail event presented above so that a direct observation of fast-mode magnetosheath wave fronts is not possible in this case.

As shown in Sect. 4, transient foreshock-like ion beams upstream but well-separated from both the bow shock and the foreshock are observed. At the same time, ground-based measurements confirm that dayside reconnection was occurring and producing FTEs propagating towards the poles. Without adequate magnetosheath observations, it is not possible to claim with certainty that the complete scenario mapped in Sect. 3 holds. Yet the observations are consistent with the first and the last part of the story, namely that while dayside reconnection is active and pulsed, a localized change in the bow shock shape causes localized ion reflection and the formation of a transient, local foreshock. It cannot be excluded that sources other than FTE-driven fast waves exist, but it is unlikely there would be distinctive features helping to tell them apart purely based on the observation of the ion beam without other measurements, from within the magnetosheath for example. Such putative sources could include unpredicted magnetosheath waves interacting with the bow shock or very localized solar wind transients not observed by the upstream spacecraft. Finally, we note that the presented scenario offers an alternative mechanism to explain transient foreshock encounters that may have been interpreted previously as foreshock skimmings due to a change in the magnetic connection of the spacecraft to the bow shock.

\section{Conclusions}

Global hybrid-Vlasov simulations of the terrestrial magnetosphere in the polar plane under constant southward IMF show that the two-dimensional equivalents of flux transfer events, formed by dayside magnetopause reconnection, drive steepening bow and stern fast-mode waves in the magnetosheath. The increased pressure behind the wave fronts causes the bow shock to bulge out, inducing favourable ion reflection conditions which can result in the generation of local, transient foreshock-like field-aligned ion beams upstream of the bow shock. The two-dimensionality of the simulation exacerbates the phenomena, but the scenario would be entirely similar in three dimensions. 
Ground-based and spacecraft observations support this scenario. During an extended period of stable southward IMF, we observe ionospheric signatures of dayside reconnection and flux transfer events in SuperDARN radar data and IMAGE magnetometer data. Simultaneously, using Geotail magnetic field and ion velocity distribution measurements we observe the expected signature of an ion beam detached both from the bow shock and the regular foreshock and not linked to any upstream magnetic field fluctuation. Further observations especially in the magnetosheath are needed though to confirm that indeed fast-mode waves lead to bow shock deformations generating localized, transient field-aligned ion beams.

\section{Data availability}

The simulation dataset is available on request from the Vlasiator team (http://vlasiator.fmi.fi, von Alfthan et al., 2014). IMAGE magnetometer data are available from http: //www.space.fmi.fi/image (Tanskanen, 2009). The AACGM software is available from http://engineering.dartmouth.edu/ superdarn/aacgm.html (Shepherd, 2014). The SuperDARN data can be accessed from the SuperDARN data portal hosted by Virginia Tech at http://vt.superdarn.org (Greenwald et al., 1995).

\section{The Supplement related to this article is available online at doi:10.5194/angeo-34-943-2016-supplement.}

Author contributions. Sebastian von Alfthan and Yann Pfau-Kempf designed and ran the simulation presented in this work. Heli Hietala helped in the analysis of the Geotail observations. Steve E. Milan provided the analysis and figure of the SuperDARN observations. Liisa Juusola provided the analysis and figure of the IMAGE observations. Yann Pfau-Kempf, Heli Hietala, Sanni Hoilijoki, Urs Ganse and Sebastian von Alfthan developed analysis tools used in this study. Minna Palmroth is the Principal Investigator of the Vlasiator team at the Finnish Meteorological Institute. Yann Pfau-Kempf led the analysis and prepared the manuscript and figures with the help of all co-authors.

Acknowledgements. The simulation was run on the Sisu supercomputer at the CSC - IT Center for Science, Espoo, Finland.

We thank T. Mukai at ISAS, JAXA in Japan for providing Geotail/LEP data; S. Kokubun at STELAB, Nagoya University, Japan for providing Geotail/MGF data; A. Szabo at NASA/GSFC for providing Wind/MFI data; K. Ogilvie at NASA/GSFC for providing Wind/SWE data; R. Lin and S. Bale at UC Berkeley for providing Wind/3DP data; M. L. Kaiser at GSFC for providing Wind/WAVES data; N. Ness at Bartol Research Institute for providing ACE/MAG data; D. J. McComas at SWRI for providing ACE/SWEPAM data; and J. H. King and N. Papatashvili at AdnetSystems and GSFC for providing OMNI data, all through CDAweb. We also thank T. Nagai and Y. Saito for providing Geotail/MGF and Geotail/LEP data through DARTS at ISAS, JAXA in Japan. We thank the University of Kyoto for providing the AE electrojet indices through the World Data Center for Geomagnetism.

We acknowledge the use of SuperDARN data. SuperDARN is a collection of radars funded by national scientific funding agencies of Australia, Canada, China, France, Japan, South Africa, United Kingdom and United States of America.

We thank the institutes who maintain the IMAGE magnetometer array.

Yann Pfau-Kempf, Sanni Hoilijoki, Sebastian von Alfthan and Minna Palmroth acknowledge financial support from the Academy of Finland under the project 267144/Vlasov. Part of this study was done by Yann Pfau-Kempf, Liisa Juusola, Urs Ganse, Sanni Hoilijoki and Minna Palmroth under the ERC CoG-682068PRESTISSIMO project, a Consolidator grant to Minna Palmroth from the European Research Council. The work of Heli Hietala is funded by NASA contract NAS5-02099. Steve E. Milan was supported by the Science and Technology Facilities Council (STFC), UK, grant no. ST/N000749/1. Urs Ganse acknowledges funding from the German Research Foundation Grant GA1968/1 and the Academy of Finland project 267186.

The topical editor, C. Owen, thanks two anonymous referees for help in evaluating this paper.

\section{References}

Amm, O.: Ionospheric elementary current systems in spherical coordinates and their application, J. Geomagn. Geoelectr., 49, 947955, doi:10.5636/jgg.49.947, 1997.

Amm, O. and Viljanen, A.: Ionospheric disturbance magnetic field continuation from the ground to ionosphere using spherical elementary current systems, Earth Planets Space, 51, 431-440, doi:10.1186/BF03352247, 1999.

Angelopoulos, V.: The THEMIS Mission, Space Sci. Rev., 141, 543, doi:10.1007/s 11214-008-9336-1, 2008.

Bavassano-Cattaneo, M. B., Bonifazi, C., Dobrowolny, M., Moreno, G., and Russell, C. T.: Distribution of MHD wave activity in the foreshock region and properties of backstreaming protons, J. Geophys. Res.-Space, 88, 9280-9286, doi:10.1029/JA088iA11p09280, 1983.

Bougeret, J. L., Kaiser, M. L., Kellogg, P. J., Manning, R., Goetz, K., Monson, S. J., Monge, N., Friel, L., Meetre, C. A., Perche, C., Sitruk, L., and Hoang, S.: WAVES: The radio and plasma wave investigation on the WIND spacecraft, Space Sci. Rev., 71, 231-263, doi:10.1007/BF00751331, 1995.

Burch, J. L., Moore, T. E., Torbert, R. B., and Giles, B. L.: Magnetospheric Multiscale Overview and Science Objectives, Space Sci. Rev., 199, 5-21, doi:10.1007/s11214-015-0164-9, 2016a.

Burch, J. L., Torbert, R. B., Phan, T. D., Chen, L.-J., Moore, T. E., Ergun, R. E., Eastwood, J. P., Gershman, D. J., Cassak, P. A., Argall, M. R., Wang, S., Hesse, M., Pollock, C. J., Giles, B. L., Nakamura, R., Mauk, B. H., Fuselier, S. A., Russell, C. T., Strangeway, R. J., Drake, J. F., Shay, M. A., Khotyaintsev, Y. V., Lindqvist, P.-A., Marklund, G., Wilder, F. D., Young, D. T., Torkar, K., Goldstein, J., Dorelli, J. C., Avanov, L. A., Oka, M., 
Baker, D. N., Jaynes, A. N., Goodrich, K. A., Cohen, I. J., Turner, D. L., Fennell, J. F., Blake, J. B., Clemmons, J., Goldman, M., Newman, D., Petrinec, S. M., Trattner, K. J., Lavraud, B., Reiff, P. H., Baumjohann, W., Magnes, W., Steller, M., Lewis, W., Saito, Y., Coffey, V., and Chandler, M.: Electron-scale measurements of magnetic reconnection in space, Science, 352, 6290, doi:10.1126/science.aaf2939, 2016b.

Burgess, D., Möbius, E., and Scholer, M.: Ion Acceleration at the Earth's Bow Shock, Space Sci. Rev., 173, 5-47, doi:10.1007/s11214-012-9901-5, 2012.

Cassak, P. A.: Inside the Black Box: Magnetic Reconnection and the Magnetospheric Multiscale Mission, Space Weather, 14, 186197, doi:10.1002/2015SW001313, 2016.

Daldorff, L. K. S., Tóth, G., Gombosi, T. I., Lapenta, G., Amaya, J., Markidis, S., and Brackbill, J. U.: Two-way coupling of a global Hall magnetohydrodynamics model with a local implicit particle-in-cell model, J. Comput. Phys., 268, 236-254, doi:10.1016/j.jcp.2014.03.009, 2014.

Davis, T. N. and Sugiura M.: Auroral electrojet activity index AE and its universal time variations, J. Geophys. Res., 71, 785-801, doi:10.1029/JZ071i003p00785, 1966.

De Hoffmann, F. and Teller, E.: Magneto-Hydrodynamic Shocks, Phys. Rev., 80, 692-703, doi:10.1103/PhysRev.80.692, 1950.

Dorelli, J. C. and Bhattacharjee, A.: On the generation and topology of flux transfer events, J. Geophys. Res.-Space, 114, A06213, doi:10.1029/2008JA013410, 2009.

Dungey, J. W.: Interplanetary Magnetic Field and the Auroral Zones, Phys. Rev. Lett., 6, 47-48, doi:10.1103/PhysRevLett.6.47, 1961.

Dunlop, M. W., Zhang, Q.-H., Bogdanova, Y. V., Lockwood, M., Pu, Z., Hasegawa, H., Wang, J., Taylor, M. G. G. T., Berchem, J., Lavraud, B., Eastwood, J., Volwerk, M., Shen, C., Shi, J.-K., Constantinescu, D., Frey, H., Fazakerley, A. N., Sibeck, D., Escoubet, P., Wild, J. A., and Liu, Z.-X.: Extended Magnetic Reconnection across the Dayside Magnetopause, Phys. Rev. Lett., 107, 025004, doi:10.1103/PhysRevLett.107.025004, 2011.

Eastwood, J. P., Balogh, A., Lucek, E. A., Mazelle, C., and Dandouras, I.: Quasi-monochromatic ULF foreshock waves as observed by the four-spacecraft Cluster mission: 1. Statistical properties, J. Geophys. Res.-Space, 110, A11219, doi:10.1029/2004JA010617, 2005a.

Eastwood, J. P., Lucek, E. A., Mazelle, C., Meziane, K., Narita, Y., Pickett, J., and Treumann, R. A.: The Foreshock, Space Sci. Rev., 118, 41-94, doi:10.1007/s11214-005-3824-3, 2005 b.

Eastwood, J. P., Phan, T. D., Fear, R. C., Sibeck, D. G., Angelopoulos, V., Øieroset, M., and Shay, M. A.: Survival of flux transfer event (FTE) flux ropes far along the tail magnetopause, J. Geophys. Res.-Space, 117, A08222, doi:10.1029/2012JA017722, 2012.

Eastwood, J. P., Phan, T. D., Cassak, P. A., Gershman, D. J., Haggerty, C., Malakit, K., Shay, M. A., Mistry, R., Øieroset, M., Russell, C. T., Slavin, J. A., Argall, M. R., Avanov, L. A., Burch, J. L., Chen, L. J., Dorelli, J. C., Ergun, R. E., Giles, B. L., Khotyaintsev, Y., Lavraud, B., Lindqvist, P. A., Moore, T. E., Nakamura, R., Paterson, W., Pollock, C., Strangeway, R. J., Torbert, R. B., and Wang, S.: Ion-scale secondary flux-ropes generated by magnetopause reconnection as resolved by MMS, Geophys. Res. Lett., 43, 4716-4724, doi:10.1002/2016GL068747, 2016.
Escoubet, C., Schmidt, R., and Goldstein, M.: Cluster - Science And Mission Overview, Space Sci. Rev., 79, 11-32, doi:10.1023/A:1004923124586, 1997.

Fear, R. C., Milan, S. E., Fazakerley, A. N., Fornaçon, K.-H., Carr, C. M., and Dandouras, I.: Simultaneous observations of flux transfer events by THEMIS, Cluster, Double Star, and SuperDARN: Acceleration of FTEs, J. Geophys. Res.-Space, 114, A10213, doi:10.1029/2009JA014310, 2009.

Fuselier, S. A., Gary, S. P., Thomsen, M. F., Bame, S. J., and Gurnett, D. A.: Ion beams and the ion/ion acoustic instability upstream from the Earth's bow shock, J. Geophys. Res.-Space, 92, 4740-4744, doi:10.1029/JA092iA05p04740, 1987.

Greenstadt, E., Russell, C., and Hoppe, M.: Magnetic field orientation and suprathermal ion streams in the Earth's foreshock, J. Geophys. Res.-Space, 85, 3473-3479, doi:10.1029/JA085iA07p03473, 1980.

Greenwald, R. A., Baker, K. B., Dudeney, J. R., Pinnock, M., Jones, T. B., Thomas, E. C., Villain, J. P., Cerisier, J. C., Senior, C., Hanuise, C., Hunsucker, R. D., Sofko, G., Koehler, J., Nielsen, E., Pellinen, R., Walker, A. D. M., Sato, N., and Yamagishi, H.: DARN/SuperDARN, Space Sci. Rev., 71, 761-796, doi:10.1007/BF00751350, 1995.

Haerendel, G., Paschmann, G., Sckopke, N., Rosenbauer, H., and Hedgecock, P. C.: The frontside boundary layer of the magnetosphere and the problem of reconnection, J. Geophys. Res.-Space, 83, 3195-3216, doi:10.1029/JA083iA07p03195, 1978.

Hasegawa, H., Kitamura, N., Saito, Y., Nagai, T., Shinohara, I., Yokota, S., Pollock, C. J., Giles, B. L., Dorelli, J. C., Gershman, D. J., Avanov, L. A., Kreisler, S., Paterson, W. R., Chandler, M. O., Coffey, V., Burch, J. L., Torbert, R. B., Moore, T. E., Russell, C. T., Strangeway, R. J., Le, G., Oka, M., Phan, T. D., Lavraud, B., Zenitani, S., and Hesse, M.: Decay of mesoscale flux transfer events during quasi-continuous spatially-extended reconnection at the magnetopause, Geophys. Res. Lett., 43, 4755-4762, doi:10.1002/2016GL069225, 2016.

Hoilijoki, S., Souza, V. M., Walsh, B. M., Janhunen, P., and Palmroth, M.: Magnetopause reconnection and energy conversion as influenced by the dipole tilt and the IMF Bx, J. Geophys. Res.Space, 119, 4484-4494, doi:10.1002/2013JA019693, 2014.

Hoilijoki, S., Palmroth, M., Walsh, B. M., Pfau-Kempf, Y., von Alfthan, S., Ganse, U., Hannuksela, O., and Vainio, R.: Mirror modes in the Earth's magnetosheath: Results from a global hybrid-Vlasov simulation, J. Geophys. Res.-Space, 121, 41914204, doi:10.1002/2015JA022026, 2016.

Kawano, H. and Russell, C. T.: Survey of flux transfer events observed with the ISEE 1 spacecraft: Dependence on the interplanetary magnetic field, J. Geophys. Res.-Space, 102, 11307-11313, doi:10.1029/97JA00481, 1997.

Kempf, Y., Pokhotelov, D., Gutynska, O., Wilson III, L. B., Walsh, B. M., von Alfthan, S., Hannuksela, O., Sibeck, D. G., and Palmroth, M.: Ion distributions in the Earth's foreshock: HybridVlasov simulation and THEMIS observations, J. Geophys. Res.Space, 120, 3684-3701, doi:doi:10.1002/2014JA020519, 2015.

Kis, A., Scholer, M., Klecker, B., Kucharek, H., Lucek, E. A., and Rème, H.: Scattering of field-aligned beam ions upstream of Earth's bow shock, Ann. Geophys., 25, 785-799, doi:10.5194/angeo-25-785-2007, 2007. 
Kokubun, S., Yamamoto, T., Acuña, M. H., Hayashi, K., Shiokawa, K., and Kawano, H.: The GEOTAIL Magnetic Field Experiment, J. Geomagn. Geoelectr., 46, 7-21, doi:10.5636/jgg.46.7, 1994.

Le, G. and Russell, C.: A study of ULF wave foreshock morphology - I: ULF foreshock boundary, Planet. Space Sci., 40, 1203-1213, doi:10.1016/0032-0633(92)90077-2, 1992.

Lepping, R. P., Acuña, M. H., Burlaga, L. F., Farrell, W. M., Slavin, J. A., Schatten, K. H., Mariani, F., Ness, N. F., Neubauer, F. M., Whang, Y. C., Byrnes, J. B., Kennon, R. S., Panetta, P. V., Scheifele, J., and Worley, E. M.: The WIND magnetic field investigation, Space Sci. Rev., 71, 207-229, doi:10.1007/BF00751330, 1995.

Lin, R. P., Anderson, K. A., Ashford, S., Carlson, C., Curtis, D., Ergun, R., Larson, D., McFadden, J., McCarthy, M., Parks, G. K., Rème, H., Bosqued, J. M., Coutelier, J., Cotin, F., D’Uston, C., Wenzel, K. P., Sanderson, T. R., Henrion, J., Ronnet, J. C., and Paschmann, G.: A three-dimensional plasma and energetic particle investigation for the WIND spacecraft, Space Sci. Rev., 71, 125-153, doi:10.1007/BF00751328, 1995.

Liu, T. Z., Hietala, H., Angelopoulos, V., and Turner, D. L.: Observations of a new foreshock region upstream of a foreshock bubble's shock, Geophys. Res. Lett., doi:10.1002/2016GL068984, 2016.

McComas, D., Bame, S., Barker, P., Feldman, W., Phillips, J., Riley, P., and Griffee, J.: Solar Wind Electron Proton Alpha Monitor (SWEPAM) for the Advanced Composition Explorer, Space Sci. Rev., 86, 563-612, doi:10.1023/A:1005040232597, 1998.

McWilliams, K. A., Sofko, G. J., Yeoman, T. K., Milan, S. E., Sibeck, D. G., Nagai, T., Mukai, T., Coleman, I. J., Hori, T., and Rich, F. J.: Simultaneous observations of magnetopause flux transfer events and of their associated signatures at ionospheric altitudes, Ann. Geophys., 22, 2181-2199, doi:10.5194/angeo-222181-2004, 2004.

Merka, J., Szabo, A., Slavin, J. A., and Peredo, M.: Threedimensional position and shape of the bow shock and their variation with upstream Mach numbers and interplanetary magnetic field orientation, J. Geophys. Res.-Space, 110, A04202, doi:10.1029/2004JA010944, 2005.

Meziane, K., Alrefay, T. Y., and Hamza, A. M.: On the shape and motion of the Earth's bow shock, Planet. Space Sci., 93-94, 1-9, doi:10.1016/j.pss.2014.01.006, 2014.

Milan, S. E., Lester, M., Cowley, S. W. H., Moen, J., Sandholt, P. E., and Owen, C. J.: Meridian-scanning photometer, coherent HF radar, and magnetometer observations of the cusp: a case study, Ann. Geophys., 17, 159-172, doi:10.1007/s00585-999-0159-5, 1999a.

Milan, S. E., Lester, M., Greenwald, R. A., and Sofko, G.: The ionospheric signature of transient dayside reconnection and the associated pulsed convection return flow, Ann. Geophys., 17, 11661171, doi:10.1007/s00585-999-1166-2, 1999b.

Milan, S. E., Lester, M., Cowley, S. W. H., and Brittnacher, M.: Convection and auroral response to a southward turning of the IMF: Polar UVI, CUTLASS, and IMAGE signatures of transient magnetic flux transfer at the magnetopause, J. Geophys. Res.Space, 105, 15741-15755, doi:10.1029/2000JA900022, 2000.

Milan, S. E., Imber, S. M., Carter, J. A., Walach, M.-T., and Hubert, B.: What controls the local time extent of flux transfer events?, J. Geophys. Res.-Space, 121, 1391-1401, doi:10.1002/2015JA022012, 2016.
Mukai, T., Machida, S., Saito, Y., Hirahara, M., Terasawa, T., Kaya, N., Obara, T., Ejiri, M., and Nishida, A.: The Low Energy Particle (LEP) Experiment onboard the GEOTAIL Satellite, J. Geomagn. Geoelectr., 46, 669-692, doi:10.5636/jgg.46.669, 1994.

Ogilvie, K. W., Chornay, D. J., Fritzenreiter, R. J., Hunsaker, F., Keller, J., Lobell, J., Miller, G., Scudder, J. D., Sittler, E. C., Torbert, R. B., Bodet, D., Needell, G., Lazarus, A. J., Steinberg, J. T., Tappan, J. H., Mavretic, A., and Gergin, E.: SWE, a comprehensive plasma instrument for the WIND spacecraft, Space Sci. Rev., 71, 55-77, doi:10.1007/BF00751326, 1995.

Øieroset, M., Lühr, H., Moen, J., Moretto, T., and Sandholt, P. E.: Dynamical auroral morphology in relation to ionospheric plasma convection and geomagnetic activity: Signatures of magnetopause $\mathrm{X}$ line dynamics and flux transfer events, J. Geophys. Res.-Space, 101, 13275-13292, doi:10.1029/96JA00613, 1996.

Omidi, N. and Sibeck, D. G.: Flux transfer events in the cusp, Geophys. Res. Lett., 34, L04106, doi:10.1029/2006GL028698, 2007.

Palmroth, M., Archer, M., Vainio, R., Hietala, H., Pfau-Kempf, Y., Hoilijoki, S., Hannuksela, O., Ganse, U., Sandroos, A., von Alfthan, S., and Eastwood, J. P.: ULF foreshock under radial IMF: THEMIS observations and global kinetic simulation Vlasiator results compared, J. Geophys. Res.-Space, 120, 8782-8798, doi:10.1002/2015JA021526, 2015.

Pang, Y., Deng, X., Yuan, Z., Zhou, M., Lin, M., Shu, Z., Li, S., Wang, J., and Balogh, A.: Polar ionosphere and geomagnetic response for the flux transfer events: A case study, Adv. Space Res., 43, 957-963, doi:10.1016/j.asr.2008.08.008, 2009.

Paschmann, G.: Recent in-situ observations of magnetic reconnection in near-Earth space, Geophys. Res. Lett., 35, L19109, doi:10.1029/2008GL035297, 2008.

Phan, T. D., Kistler, L. M., Klecker, B., Haerendel, G., Paschmann, G., Sonnerup, B. U. Ö., Baumjohann, W., Bavassano-Cattaneo, M. B., Carlson, C. W., DiLellis, A. M., Fornacon, K.-H., Frank, L. A., Fujimoto, M., Georgescu, E., Kokubun, S., Moebius, E., Mukai, T., Øieroset, M., Paterson, W. R., and Reme, H.: Extended magnetic reconnection at the Earth's magnetopause from detection of bi-directional jets, Nature, 404, 848-850, doi:10.1038/35009050, 2000.

Pokhotelov, D., von Alfthan, S., Kempf, Y., Vainio, R., Koskinen, H. E. J., and Palmroth, M.: Ion distributions upstream and downstream of the Earth's bow shock: first results from Vlasiator, Ann. Geophys., 31, 2207-2212, doi:10.5194/angeo31-2207-2013, 2013.

Provan, G., Yeoman, T. K., and Milan, S. E.: CUTLASS Finland radar observations of the ionospheric signatures of flux transfer events and the resulting plasma flows, Ann. Geophys., 16, 14111422, doi:10.1007/s00585-998-1411-0, 1998.

Russell, C. T. and Elphic, R. C.: Initial ISEE magnetometer results: magnetopause observations, Space Sci. Rev., 22, 681-715, doi:10.1007/BF00212619, 1978.

Russell, C. T. and Elphic, R. C.: ISEE observations of flux transfer events at the dayside magnetopause, Geophys. Res. Lett., 6, 3336, doi:10.1029/GL006i001p00033, 1979.

Sanderson, T. R., Reinhard, R., Wenzel, K.-P., Roelof, E. C., and Smith, E. J.: Observations of upstream ions and lowfrequency waves on ISEE 3, J. Geophys. Res.-Space, 88, 85-95, doi:10.1029/JA088iA01p00085, 1983.

Schwartz, S. J., Thomsen, M. F., and Gosling, J. T.: Ions upstream of the Earth's bow shock: A theoretical comparison of alterna- 
tive source populations, J. Geophys. Res.-Space, 88, 2039-2047, doi:10.1029/JA088iA03p02039, 1983.

Schwartz, S. J., Daly, P. W., and Fazakerley, A. N.: Multi-spacecraft analysis of plasma kinetics, in: Analysis methods for multispacecraft data, edited by: Paschmann, G. and Daly, P. W., ISSI Scientific Reports, International Space Science Institute, 1, 159$183,2000$.

Shepherd, S. G.: Altitude-adjusted corrected geomagnetic coordinates: Definition and functional approximations, J. Geophys. Res.-Space, 119, 7501-7521, doi:10.1002/2014JA020264, 2014.

Sibeck, D. and Omidi, N.: Flux transfer events: Motion and signatures, J. Atmos. Sol.-Terr. Phy., 87-88, 20-24, doi:10.1016/j.jastp.2011.07.010, 2012.

Smith, C., L'Heureux, J., Ness, N., Acuña, M., Burlaga, L., and Scheifele, J.: The ACE Magnetic Fields Experiment, Space Sci. Rev., 86, 613-632, doi:10.1023/A:1005092216668, 1998.

Tanskanen, E. I.: A comprehensive high-throughput analysis of substorms observed by IMAGE magnetometer network: Years 1993-2003 examined, J. Geophys. Res., 114, A05204, doi:10.1029/2008JA013682, 2009.

Thomsen, M. F., Schwartz, S. J., and Gosling, J. T.: Observational evidence on the origin of ions upstream of the Earth's bow shock, J. Geophys. Res.-Space, 88, 7843-7852, doi:10.1029/JA088iA10p07843, 1983.

Trattner, K. J., Mulcock, J. S., Petrinec, S. M., and Fuselier, S. A.: Probing the boundary between antiparallel and component reconnection during southward interplanetary magnetic field conditions, J. Geophys. Res.-Space, 112, A08210, doi:10.1029/2007JA012270, 2007.

Treumann, R. A. and Baumjohann, W.: Collisionless Magnetic Reconnection in Space Plasmas, Frontier. Phys., 1, 31, doi:10.3389/fphy.2013.00031, 2013.

van de Kamp, M.: Harmonic quiet-day curves as magnetometer baselines for ionospheric current analyses, Geosci. Instrum. Method. Data Syst., 2, 289-304, doi:10.5194/gi-2-289-2013, 2013. von Alfthan, S., Pokhotelov, D., Kempf, Y., Hoilijoki, S., Honkonen, I., Sandroos, A., and Palmroth, M.: Vlasiator: First global hybrid-Vlasov simulations of Earth's foreshock and magnetosheath, J. Atmos. Sol.-Terr. Phy., 120, 24-35, doi:10.1016/j.jastp.2014.08.012, 2014.

Weygand, J. M., Amm, O., Angelopoulos, V., Milan, S. E., Grocott, A., Gleisner, H., and Stolle, C.: Comparison between SuperDARN flow vectors and equivalent ionospheric currents from ground magnetometer arrays, J. Geophys. Res., 117, A05325, doi:10.1029/2011JA017407, 2012

Wild, J. A., Cowley, S. W. H., Davies, J. A., Khan, H., Lester, M., Milan, S. E., Provan, G., Yeoman, T. K., Balogh, A., Dunlop, M. W., Fornaçon, K.-H., and Georgescu, E.: First simultaneous observations of flux transfer events at the high-latitude magnetopause by the Cluster spacecraft and pulsed radar signatures in the conjugate ionosphere by the CUTLASS and EISCAT radars, Ann. Geophys., 19, 1491-1508, doi:10.5194/angeo-191491-2001, 2001

Wild, J. A., Milan, S. E., Cowley, S. W. H., Dunlop, M. W., Owen, C. J., Bosqued, J. M., Taylor, M. G. G. T., Davies, J. A., Lester, M., Sato, N., Yukimatu, A. S., Fazakerley, A. N., Balogh, A., and Rème, H.: Coordinated interhemispheric SuperDARN radar observations of the ionospheric response to flux transfer events observed by the Cluster spacecraft at the high-latitude magnetopause, Ann. Geophys., 21, 1807-1826, doi:10.5194/angeo-211807-2003, 2003.

Wilson, L. B., Koval, A., Sibeck, D. G., Szabo, A., Cattell, C. A., Kasper, J. C., Maruca, B. A., Pulupa, M., Salem, C. S., and Wilber, M.: Shocklets, SLAMS, and field-aligned ion beams in the terrestrial foreshock, J. Geophys. Res.-Space, 118, 957-966, doi:10.1029/2012JA018186, 2013.

Zweibel, E. G. and Yamada, M.: Magnetic Reconnection in Astrophysical and Laboratory Plasmas, Annu. Rev. Astron. Astr., 47, 291-332, doi:10.1146/annurev-astro-082708-101726, 2009. 